\title{
Screening Reactor Steam/Water Piping Systems for Water Hammer
}

Manuscript Completed: August 1997

Date Published: September 1997

Prepared by

P. Griffith

Massachusetts Institute of Technology 77 Massachusetts Avenue

Cambridge, MA 02139

D. Bessette, NRC Project Manager

Prepared for

Division of Systems Technology

Office of Nuclear Regulatory Research

U.S. Nuclear Regulatory Commission

Washington, DC 20555-0001

NRC Job Code J6008

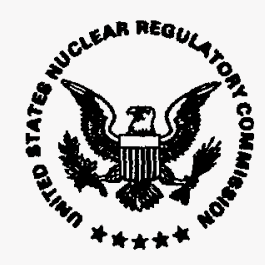




\begin{abstract}
A steam/water system possessing a certain combination of thermal, hydraulic and operational states, can, in certain geometries, lead to a steam bubble collapse induced water hammer. These states, operations, and geometries are identified. A procedure that can be used for identifying whether an unbuilt reactor system is prone to water hammer is proposed.

For the most common water hammer, steam bubble collapse induced water hammer, six conditions must be met in order for one to occur. These are:
1) the pipe must be almost horizontal,
2) the subcooling must be greater than $20^{\circ} \mathrm{C}$.

Abstract
3) the L/D must be greater than 24 .

4) the velocity must be low enough so that the pipe does not run full, i.e., the Froude number must be less than one.

5) there should be void nearby.

6) the pressure must be high enough so that significant damage occurs, that is the pressure should be above 10 atmospheres.

Recommendations on how to avoid this kind of water hammer in both the design and the operation of the reactor system are made. 


\section{DISCLAMIER}

Portions of this document may be illegible in electronic image products. Images are produced from the best available original document. 


\section{Contents}

Abstract $\quad$ iii

Contents $\quad$ v

List of Figures

List of Symbols $\quad$ ix

List of Tables $\quad$ xi

Executive Summary $\quad$ xiii

$\begin{array}{lll}\text { Introduction } & 1.0 & 1\end{array}$

$\begin{array}{ll}\text { Section } 2.0 & \text { Steam bubble collapse induced water hammers and severe } \\ \text { fluid transients }\end{array}$

Section 2.1 Water hammers due to the stratified to slug flow transition

Section 2.2 Conditions leading to SBCIWH due to the transition to slug flow 5

Section 2.3 Admitting cold water in down flow into a blocked, $\begin{array}{ll}\text { vertical steam-filled pipe } & 7\end{array}$

Section 2.4 Draining an inclined pipe which is originally filled with cold water, the presence of steam

Section 2.5 Column separation and rejoining and refilling voided pipes

Section 2.6 Pump start

Section 2.7 Passive water hammer 9

Section 2.8 Chugging 10

$\begin{array}{lll}\text { Section } 2.9 & \text { Pipe clearing transients } & 10\end{array}$

Section 3.0 Estimating the severity and duration of a steam bubble collapse induced water hammer (SBCIWH)

Section 4.0 Pipe clearing transient description $\quad 15$

$\begin{array}{lll}\text { Section 5.0 Experience in existing LWR's } & 21\end{array}$

$\begin{array}{lll}\text { Section 5.1 Screening an unbuilt system for water hammers } & 21\end{array}$

Section 5.2 Comments on specific components identified on

$\begin{array}{ll}\text { Figure (5-3) } & 27\end{array}$

$\begin{array}{lll}\text { Section } 5.21 & \text { Surge line } & 27\end{array}$

Section 5.22 DVI line 27

Section 5.23 DVI nozzle $\quad 27$

Section 5.24 ADS1-3 sparger $\quad 27$

Section 5.25 CMT drain $\quad 27$

$\begin{array}{lll}\text { Section 5.26 PRHR HX } & 27\end{array}$

Section 5.27 Hot leg/cold leg $\quad 28$

Section 5.28 ADS1-3 depressurization valves $\quad 28$

$\begin{array}{ll}\text { Section 5.29 } & \begin{array}{l}\text { Discussion of the screening criteria used for SBCIWH } \\ \text { due to the stratified/slug transition }\end{array}\end{array}$ 
Appendix A Calculating the allowable system pressure to insure that steam bubble collapse induced water hammer won't lead to failure

References 


\section{List of Figures}

Fig. 2-1 The stratified to slug transition; as it leads to steam bubble collapse induced water hammer in a horizontal pipe. Reference (4).

Fig. 2-2 The effect of subcooling on the region where steam bubble collapse induced water hammer can occur. Reference (5).

Fig. 2-3 The stratified to slug transition in a draining pipe. (a) Low velocity drainage. $\mathrm{Fr}_{\mathrm{d}}<44$. (b) High velocity drainage. $\mathrm{Fr}_{\mathrm{d}}>44$, Equation (2-3). Reference (14).

Fig. 2-4 The stability map for a draining pipe with inclination angle from the horizontal as the primary variable. Reference (14).

Fig. 3-1 A bubble trapped between a column of cold water and a slug of liquid.

Fig. 3-2 The variation of the velocity of the slug as a function of time showing the inertia limit and the wall sheer stress limits as well as the actual velocity.

Fig. 4-1 (a) The actual configuration of water trapped in a low point in a pipe and (b) the assumed configuration when the pipe is cleared by a flow of steam or air from the left. References (11) and (12).

Fig. 4-2 Force-time data from the pipe clearing experiments of Reference (11). The top figure is a summary of the peak forces measured. The cartoons at the bottom are samples of the measured force-time traces for selected initial liquid fractions upstream of the force transducer.

Fig. 4-3 The decay of the peak force as a function of the distance 19 a slug travels. If enough straight pipe is provided after the trap or loop seal, the clearing force downstream can be reduced to manageable values. Reference (11).

Fig. 4-4 Impulse durations for pipe clearing experiment.

Reference (11). 
Fig. 5-1 Schematic of the AP600 reactor system showing locations that should be checked for steam bubble collapse induced water hammers or severe fluid transients.

Fig. A-1 The velocity of sound in: (a) saturated water and saturated steam, (b) two-phase mixtures (homogeneous). Reference (2).

Fig. A-2 The peak steam bubble collapse induced water hammer pressures observed in the simulated cold leg as a function of pressure tap location. Reference (13).

Fig. A-3 Peak steam bubbble collapse induced pressure measured 36 in the apparatus shown at the upper right. Reference (16). 


\section{List of Symbols}

\begin{tabular}{ll}
$A_{x}$ & Cross section area, $\mathrm{m}^{2}$ \\
$\mathrm{C}$ & Velocity of sound, $\mathrm{m} / \mathrm{s}$ \\
$\mathrm{C}_{\mathrm{f}}$ & Velocity of sound in liquid water, $\mathrm{m} / \mathrm{s}$ \\
$\mathrm{C}_{\mathrm{g}}$ & Velocity of sound in water vapor, $\mathrm{m} / \mathrm{s}$ \\
$\mathrm{D}$ & Pipe diameter, $\mathrm{m}$ \\
$\mathrm{F}$ & Force, $\mathrm{N}$ \\
$\mathrm{F}^{*}$ & Dimensionless force \\
$\mathrm{F}_{\mathrm{max}}$ & Maximum force, $\mathrm{N}$ \\
$\mathrm{g}$ & Acceleration of gravity, $\mathrm{m} / \mathrm{s}^{2}$ \\
$\mathrm{I}$ & Impulse, $\mathrm{N}$ \\
$\mathrm{I}^{*}$ & Dimensionless impulse \\
$\mathrm{K}$ & Dimensionless stopping constant, 1 for a pipe end, \\
& 0.5 for a column of liquid \\
$\mathrm{L}$ & Length, $\mathrm{m}$ \\
$\mathrm{L}_{\mathrm{b}}$ & Bubble length, $\mathrm{m}$ \\
$\mathrm{L}_{\mathrm{s}}$ & Slug length, $\mathrm{m}$ \\
$\mathrm{m}$ & Mass, kg \\
$\mathrm{P}$ & Pressure, Pa \\
$\mathrm{P}_{\mathrm{o}}$ & System pressure, Pa \\
$\mathrm{T}$ & Temperature, $\mathrm{K}$ \\
$\mathrm{T}_{\mathrm{s}}$ & Saturation temperature, $\mathrm{K}$ \\
$\mathrm{t}_{\mathrm{n}}$ & Time, $\mathrm{s}$ \\
$\mathrm{V}$ & Nominal time, $\mathrm{s}$ \\
& Dimensionless time \\
& Velocity, $\mathrm{m} / \mathrm{s}$ \\
\hline &
\end{tabular}




$\begin{array}{ll}\vartheta_{\mathrm{b}} & \text { Bubble volume, } \mathrm{m}^{3} \\ \mathrm{~V}_{\mathrm{g}} & \text { Vapor velocity, } \mathrm{m} / \mathrm{s} \\ \vartheta_{\mathrm{s}} & \text { Slug volume, } \mathrm{m}^{3} \\ \mathrm{~V}_{\mathrm{n}} & \text { Nominal velocity, } \mathrm{m} / \mathrm{s}\end{array}$

$\alpha \quad$ Void fraction dimensionless

$\rho_{\mathrm{f}} \quad$ Liquid density, $\mathrm{kg} / \mathrm{m}^{3}$

$\rho_{\mathrm{g}} \quad$ Vapor density, $\mathrm{kg} / \mathrm{m}^{3}$

$\theta \quad$ Slope angle measured from horizontal

NUREG/CR-6519

$x$ 


\section{List of Tables}

Table 5.1 Water hammer events reported in PWR plant

Table 5.2 Water hammer events reported in PWR plant

24

Table 5.3 Components and their associated types of water

26 hammers or severe fluid transients 


\section{Executive Summary}

The various causes of Steam Bubble Collapse Induced Water Hammer (SBCIWH) are examined and the underlying conditions for an SBCIWH to occur have been identified. With the exception of filling a long, horizontal steam-filled pipe with cold water, it appears that these water hammers can be eliminated either at the design stage or by adopting suitable operating procedures. The problem that remains when a plant is properly designed and operated is how to refill a horizontal or almost horizontal steam-filled pipe with cold water without inducing a water hammer. This process is intrinsic to the advanced reactor passive safety systems. The conditions that must exist for a SBCIWH to occur in this geometry are identified and a method proposed for screening a system at the design stage. The proposed method is designed to be used with computed (RELAP) results for determining the fluid state in various components during the transients and accidents of interest.

The criteria for screening a system for SBCIWH have been identified and are as follows. For a SBCIWH to occur during refilling of horizontal pipes:

1. The pipe must be horizontal or almost horizontal (the slope less than $2.4^{\circ}$ ).

2. The water must be subcooled to more than $20^{\circ} \mathrm{C}$.

3. The L/D must be greater than 24 .

4. The filling velocity for the cold water, based on the full pipe area, must be such that the
Froude Number $\left[\mathrm{V} /(\mathrm{gD})^{1 / 2}\right]$ is less than 1.

5. There must be void nearby.

6. The system pressure must be great enough so that the water slugs will impact the affected parts of the system at a high enough velocity to do damage. This threshold system pressure appears to be somewhere between 100 to 300 psia ( 1 to $3 \times 10^{6} \mathrm{~Pa}$ ) depending on the criteria chosen for deciding what constitutes an intolerable SBCIWH.

An example of how to screen a design (based on an artist's conception of the layout for the AP 600) is presented. The components and features that might suffer a SBCIWH are identified and the elimination, mitigation or accommodation techniques for each component that might experience a SBCIWH is suggested. The most important areas for which additional work is needed are as follows:

1. The most limiting mode of failure if a SBCIWH occurs in a steam system needs to be identified.

2. Some higher pressure and larger pipe water hammer data are needed to see if we have forgotten anything.

3. A decision as to what constitutes a system that is safe enough needs to be made as the recommended screening criteria are quite conservative.They will "predict" many water hammers that will never occur.

4. The subcooling at which SBCIWH is a problem at elevated pressures is not known. 


\subsection{Introduction}

The proposed advanced light water reactors differ from existing light water reactors primarily in their safety systems. In the event of an accident, like a LOCA, the advanced light water reactors are designed to be blown down and then reflooded using a gravity driving head. The unique geometries and modes of operating this system will insure that some operating states which have never before been entered in the existing light water reactors, will be entered into here.

The conditions of concern which are new include:

A partially voided primary

The presence of subcooled water

A low reflood velocity

A variety of potential water hammerprone geometries.

The purpose of this report is to identify those geometries, operations and states which lead to water hammers so that, by design or operational changes, the problem can be identified and then eliminated, accommodated, or its effects mitigated.

Water hammer occurs in piping systems which experience rapid changes in velocity. These changes in velocity occur over such a short time period that the resulting pressure waves cannot travel the length of the pipe before the change in velocity is complete. A brief description of water hammer can be found in Mark's Handbook (1). A more complete description is available in Moody (2). For the purposes of this report however, only the simplest ideas from these sources will be used. Where two phases are concerned, the uncertainties associated with the two-phase flow configuration itself, overwhelm the other uncertainties so that only simple equations or ideas turn out to be useful.

The most important equation which we'll need is the Jukowski equation, Reference 1. If a pipe which is filled with flowing water is suddenly closed at the discharge end, a water hammer will occur. The resulting pressure wave will travel back to the reservoir where the flow originates at the velocity of sound for a pressure wave in that pipe. The resulting pressure rise for a rigid pipe will be

$$
\Delta P=K \rho_{f} C(\Delta V)
$$

In this equation,

$$
\begin{aligned}
& \Delta P=\text { the resulting pressure rise in } \\
& \Delta V=\text { the extinguished velocity in } \mathrm{m} / \mathrm{s} \text {. } \\
& \rho_{f}=\text { the density of the flowing liquid } \\
& \mathrm{kg} / \mathrm{m}^{3} \text {. }
\end{aligned}
$$

Pipe elasticity, end connections, fittings, wall friction, bubbles and multidimensional effects all complicate the picture but because two phase flows have such complex configurations and behavior to start with, the above equation with an appropriate velocity of sound is good enough for practically all our purposes. The uncertainties associated with the configuration of the phase boundaries and the heat and mass transfer processes occurring on these boundaries overwhelm the other uncertainties in this equation. Much of this report will be concerned with predicting what conditions lead to water hammer in steam systems and giving recommendations on how to evaluate each of the terms in Equation (1-1).

While water hammer is hardly unknown in nuclear systems, for the currently operating PWR's the way they are built and operated precludes dangerous water hammers in the primary. The combination of high pressure, void, and subcooled water which is necessary for a serious steam bubble collapse induced water hammer to occur is never present. Auxiliary systems such as service water, auxiliary feed water systems, and so 
forth have, sometimes, suffered water hammers (3), but many of the auxiliary systems that have experienced water hammers are not safety related and thus fall outside the area of NRC concern. The advanced light water reactors, however, are different.

The advanced LWR's use safety systems which involve blowing down the primary for certain kinds of transients. High pressure, void, and cold water can coexist at various places in the primary during the blow down or the refilling process. This combination can lead to steam bubble collapse induced water hammers which might then challenge the primary system in some way. This report is written to provide guidelines which will help the NRC to screen a new design and identify the design features, possible equipment failure modes and system operating procedures which could lead to unexpected and dangerous water hammers.

Water hammers in nuclear systems can be handled using one of three strategies: elimination, mitigation, or accommodation. Often water hammer can be eliminated at the design stage by modest changes in the geometry. This is the best option. Even geometries which might incur a steam bubble collapse induced water hammer can often be operated so that they are eliminated. For existing plants, which might actually have a water hammer problem, operational controls are often sufficient to eliminate this concern.

Under certain circumstances, steam bubble collapse induced water hammers are inevitable but their consequences mitigated by the adoption of clever designs or suitable operating procedures. Controlled filling or putting in non-condensable gases will often mitigate the effects of water hammers sufficiently so that we can live with the possibility that they will occur.

Lastly, a system can be designed so that the steam bubble collapse induced water hammers, even if they are inevitable, can be accommodated. The piping and supports can be made robust enough so that the water hammers cannot damage the system. This choice of strategies means that with foresight and good design, steam bubble collapse induced water hammer (SBCIWH) will not be a problem in a nuclear system.
In the remainder of this report the various kinds of steam bubble collapse induced hammers will be described. Fluid transients characteristic of two phase systems, but normally excluded from classical water hammer treatments will also be touched upon. The geometries and fluid conditions that lead to these water hammers will be identified and various elimination, mitigation, or accommodation strategies will be suggested as appropriate.

Any complex, high-performance piping system, such as a nuclear plant, is designed to ride out a wide variety of single phase fluid transients. These transients are not the subject of this report. They are already satisfactorily handled by procedures universally adopted in the industry. Single-phase flows are not our concern.

Our understanding of the processes leading to steam system water hammers and their consequences now allows us to construct a screening procedure that can be used on a plant, at the design stage, to identify those features and procedures that might lead to dangerous water hammers. The proposed screening procedure will be illustrated by an example which will make the use of the suggested screening criteria clear. 


\subsection{Steam bubble collapse induced water hammers and severe fluid}

transients: The water hammers that occur in steam systems (which often actually contain both steam and water) can occur for a great variety of reasons. In this section we shall categorize the geometries and processes that cause these water hammers and provide guidance as to how to predict if they will occur. Several other classification schemes, aside from the one chosen here, are in use and could have been used to categorize these events. The sub-system in which it occurs could be used to characterize it. (3) The component could be used. (5) The process or physical mechanism could be used to categorize it. I've chosen to categorize the SBCIWH by their physical mechanism. This selection means that repetitious descriptions of how they occur are minimized and only a few equations will suffice to provide the answers we need.

\subsection{Water hammers due to the} stratified to slug flow transition: This is the most common cause of water hammers in steam systems and occurs and reoccurs in a variety of geometries and scenarios. This mechanism was first identified and described in Reference (15) and was subsequently analyzed in Reference (4). For the details of the description and analysis, it is recommended that these references be consulted. In essence, the processes leading to this kind of water hammer are as follows.

A horizontal pipe, typically, initially filled with steam and having access to a reservoir of steam at one end, experiences a flow of cold water into the other end. The velocity of the flow is low enough so that a tongue of cold water advances into the steam filled pipe. This is called a stratified flow. Condensation occurs on this tongue which, if the tongue is long enough, leads to a counterflow of steam and water on the tongue. This counterflow becomes sufficiently vigorous so that first a wave, and then a plug forms. This is the transition to slug flow. These processes are illustrated in Figure (2-1).

The steam bubble which is shown in the (c) cartoon of Figure (2-1) is surrounded by cold water. This causes the steam pressure in the bubble to drop to a value which is close to the saturation pressure associated with the temperature of the cold liquid. This pressure is usually so low, that the liquid to the right of the bubble is rapidly accelerated to a velocity high enough to cause a significant water hammer when the condensation is complete. A pressure wave, the magnitude of which can be calculated from Equation (1-1) proceeds to the left and right of Figure (2-1)(d). The right traveling wave hits the free surface and is dissipated at the bubbly interface. A pressure wave, about equal to the steam pressure, then proceeds from the free surface back towards the point of origin and then beyond.

While this is going on, a similar pressure wave is proceeding to the left. These two waves act to give rise to large, short duration forces on the pipes which are often sufficient to damage them or the pipe supports.

The well-established procedures for calculating the forces resulting from water hammers in cold water piping systems are not appropriate for typical steam systems. Occasional trapped bubbles of steam or noncondensable gases, indistinct or unpredictable interface locations and intricate component geometries all lead to a rapid amplitude reduction and wave broadening for the pressure wave front. This is why there is very little experimental evidence in steam systems of clean wave reflection from the free surface at the right of Figure (2-1)(d). In this section the circumstances leading to SBCIWH will be explored. In Section (3) and Appendix A, we will describe in detail how to estimate the peak pressure when the slug of liquid, such as the one at the right in Figure (2-1), hits the column of subcooled liquid shown on the left. 

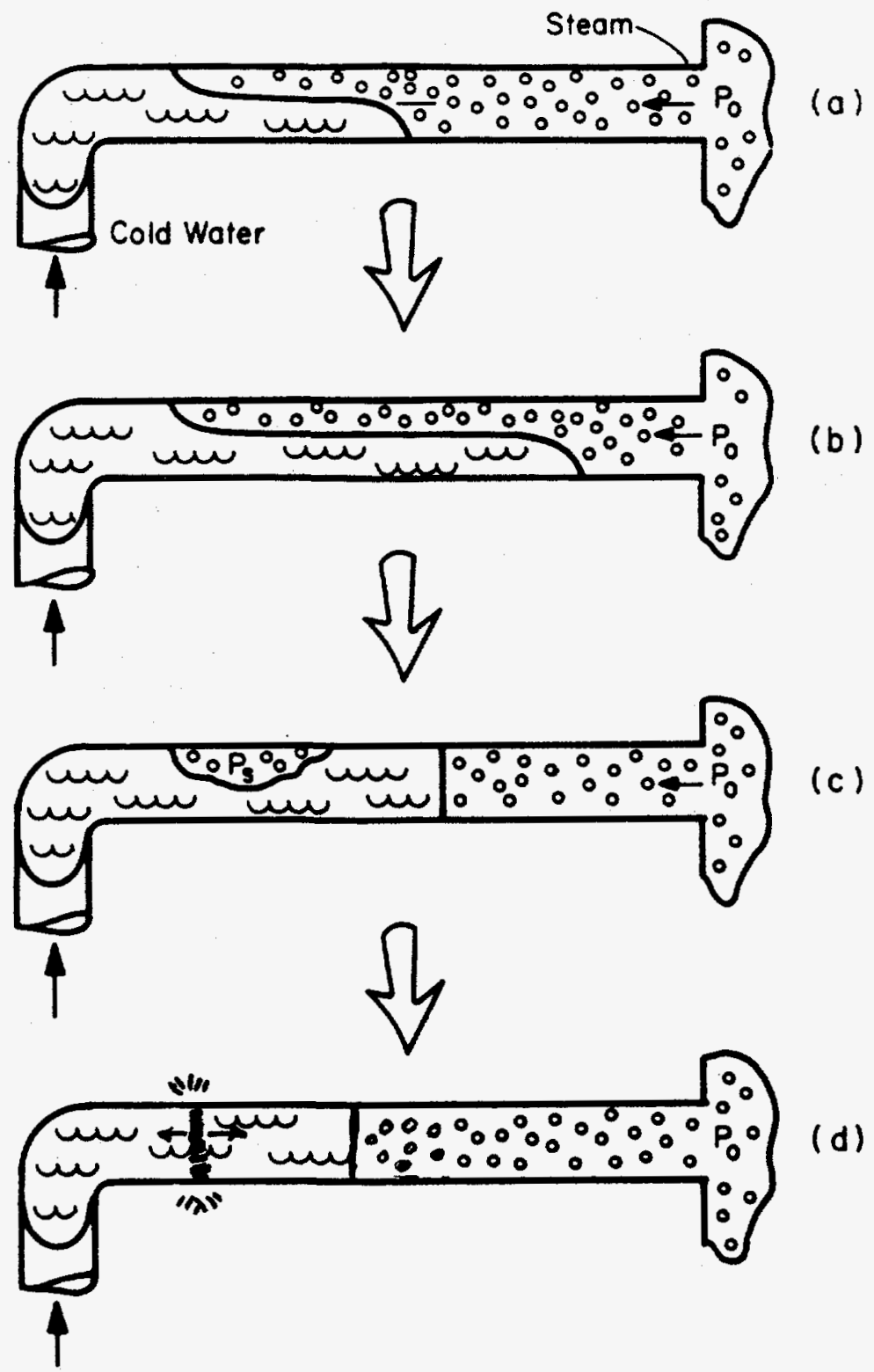

(d)

Figure 2-1. The stratified to slug transition as it leads to steam bubble collapse induced water hammer in a horizontal pipe.

Reference (4). 


\subsection{Conditions leading to SBCIWH} due to the transition to slug flow.

Both Reference (5), the thesis on which it is based, and Reference (4) give stability maps showing under what circumstances SBCIWH can occur. The criteria for SBCIWH were simplified and worked out numerically for a wide range of conditions and published in Reference (6). One of the figures from Reference (5) is reproduced here as Figure (22). For a convenient screening procedure, there are far too many parameters in this problem to work out all possibilities in detail, so we shall simplifiy these criteria and start with the minimum subcooling and minimum water flow rate which are present if a water hammer is to occur.

Let us start by explaining Figure (2-2). It is clear, with a little consideration, that some subcooling is essential if steam bubble collapse induced water hammer is to occur. Until something like $20^{\circ} \mathrm{K}$ of subcooling is present, the range of pipe-filling flow rates over which SBCIWH occurs is very small. (See appendix A). This subcooling limit, which is based entirely on experience in low pressure systems, is thought to be generally conservative. The first part of the simplified screening criteria is, therefore:

$$
\left(\mathrm{T}_{\mathrm{S}}-\mathrm{T}\right)>20^{\circ} \mathrm{C}
$$

if SBCIWH is to occur. In equation (2-1),

$$
\begin{aligned}
& \mathrm{T}_{\mathrm{S}}=\begin{array}{l}
\text { Saturation temperature for the } \\
\text { nominal local pressure in }
\end{array}{ }^{\circ} \mathrm{K} . \\
& \mathrm{T}=\text { The actual temperature of } \\
& \text { the water in }{ }^{\circ} \mathrm{K} .
\end{aligned}
$$

There is a water-hammer-free region at the lower left of Figure (2-2), (labeled stable or metastable) where SBCIWH does not occur. This is because the water flow rate and the resulting liquid fraction is so low that a transition to slug flow is not possible. A transition to slug flow requires a liquid fraction greater than 0.2 . Immediately adjoining the stable region on Figure (2-2) is a metastable region in which the conditions for SBCIWH are marginal in that the condensation events are not vigorous enough to cause one. We did not find water hammers in this region in our experiments. The benefits that these water-hammer-free regions confer on a system will not be exploited in the proposed screening procedure. Rather, we will assume that whenever the sub-cooling is large enough and the filling velocity is less than the critical velocity shown at the top of Figure (2-2), that a water hammer will occur. Let us now focus more closely on this limit.

If a horizontal pipe has a small water flow rate and the end is open to a steam (or gas-filled volume), the pipe won't run full. If the gas phase is steam, this pipe can experience an SBCIWH. If, on the contrary, the flow rate is high enough, the pipe runs full and the area exposed to the steam is so small that not much condensation will occur. The counter-current flow needed to cause a transition to slug flow cannot be set up. As long as the pipe runs full, SBCIWH will not occur. An approximate conservative criterion for the pipe running full so that a water hammer cannot occur is,

$$
\frac{V_{f s}}{\sqrt{g D}}>1
$$

In equation (2-2),

$$
\begin{aligned}
& \mathrm{V}_{\mathrm{fs}}=\text { The superficial velocity of } \\
& \text { liquid water in the pipe in } \mathrm{m} / \mathrm{s} \text {. } \\
& \mathrm{g}=\underset{\mathrm{The}}{\mathrm{m} / \mathrm{s}^{2}} \\
& \mathrm{D}=\text { The pipe diameter in meters. }
\end{aligned}
$$

This is one of the most important screening criteria for SBCIWH.

Though these criteria were developed in connection with filling a horizontal pipe, the underlying mechanism of water hammer which arises in horizontal pipes, also appears in a variety of other scenarios and geometries. The next few sections will describe these. 


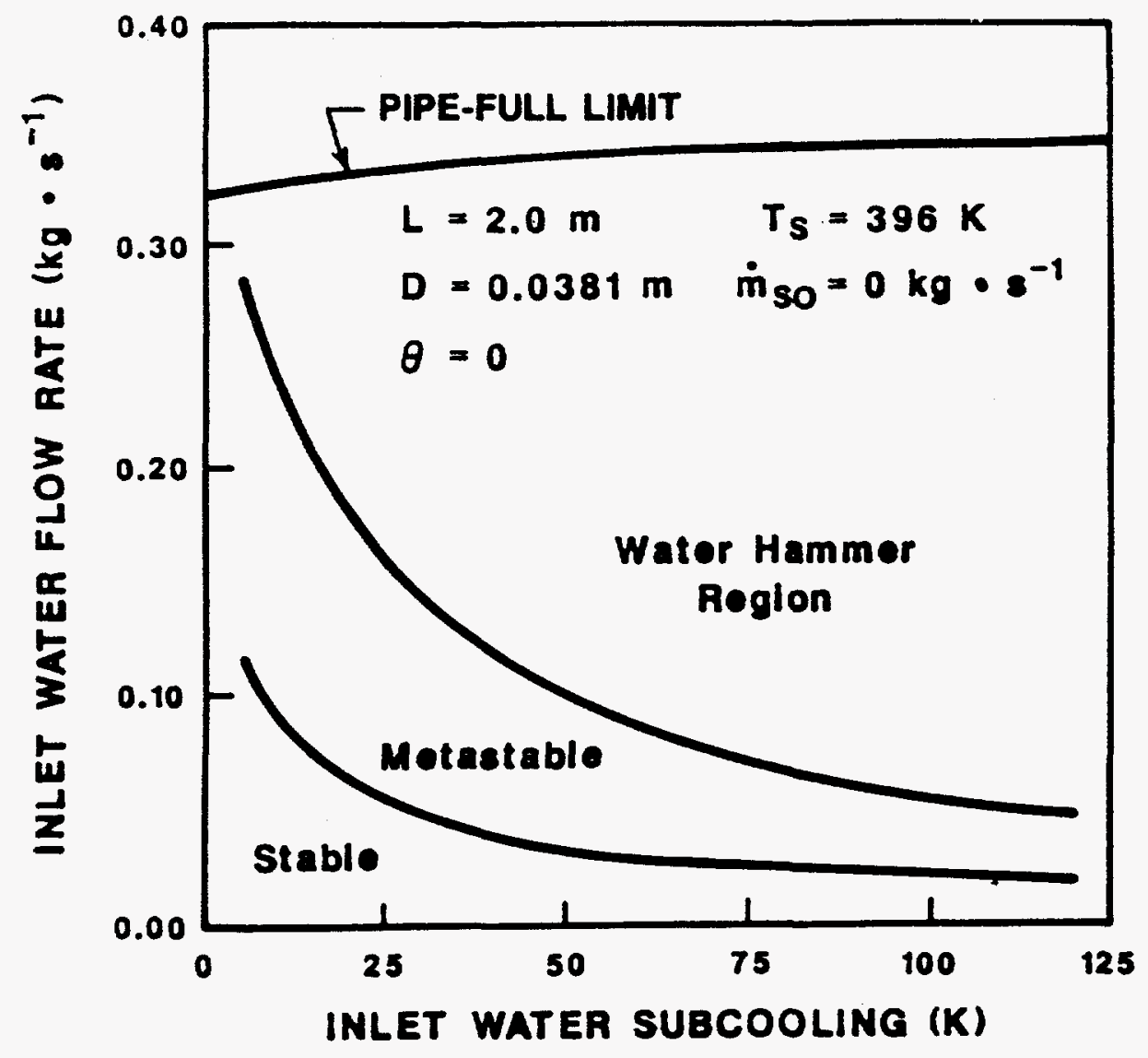

Figure 2-2. The effect of subcooling on the region where steam bubble collapse induced water hammer can occur. Reference (5). 


\subsection{Admitting cold water in down} flow into a blocked, vertical, steamfilled pipe. For a small flow rate of cold water into the top of an empty vertical pipe, one obtains an annular or rivulet flow pattern. As the cold water flow rate is increased, the void fraction decreases. Somewhere in the range of void fraction between 0.7 or 0.8 , a transition to slug flow occurs. This transition leads to the trapping of large steam bubbles which are surrounded by cold water. A very rapid condensation of these bubbles can occur which can lead to a water hammer. (Reference 7).

In general, admitting cold water above steam is a poor practice because it often results in trapping a steam bubble. Trapping can lead to a violent bubble collapse and a water hammer. Filling steam-filled pipes or other volumes with cold water from below, on the other hand, is usually a smooth process. The cold water entering the pipe, quickly acquires a thin layer on top which is close to the steam saturation temperature. This layer greatly reduces the condensation rate and with it, the possibility of counter current, stratified flow. This layer is stabily stratified and no condensation event occurs. (A condensation event, in general, is a rapid condensation and mixing where the mixing is driven by the motion due to the condensation itself.) $(6,7)$.

This kind of water hammer is due primarily, to a poor choice of piping geometry, and is best eliminated by a design change. Filling short pipes of any orientation can lead to problems too. (Reference 7). Whether this will occur in an untested system, however, cannot be determined without examining detailed piping drawings in the context of a well-defined scenario. Reference (7) gives the details needed for screening other geometries; a low point in any voided system is prone to this kind of water hammer.

\subsection{Draining an inclined pipe, which} is originally filled with cold water, in the presence of steam. One of the more counterintuitive processes that can lead to SBCIWH is draining a pipe which has cold water in it, while simultaneously refilling it with steam. This process often occurs when a steam system has been turned off for several days. The low parts have filled with condensate which has had a chance to cool. The drain is opened to remove this condensate, the condensate level drops and, for sufficiently rapid draining, the water which is left behind collects into a wave which then leads to a transition to slug flow. Figure (2-3), (Reference 14) shows how the flow regime changes in going from slow drainage to rapid while Figure (2-4) is a map which shows where water hammers occur.

This kind of water hammer can be categorically eliminated by keeping the draining Froude number, $\mathrm{Fr}_{\mathrm{d}}$, as defined in equation (2-3), to a value less than 44 , and by suitably inclining the pipes. For draining inclined pipes,

$$
\mathrm{Fr}_{\mathrm{d}} \equiv \frac{\rho_{f} V_{f s}^{2}}{\left(\rho_{f-} \rho_{g}\right) g D \operatorname{Sin} \theta}
$$

where, $\quad \mathrm{Fr}_{\mathrm{d}} \leq 44$

in order to preclude water hammers. This is a water hammer that should never occur.

In equation (2-3),

$$
\begin{aligned}
& \mathrm{Fr}_{\mathrm{d}}=\begin{array}{c}
\text { The Froude number for } \\
\text { draining, dimensionless }
\end{array} \\
& \rho_{\mathrm{f}}=\text { the liquid density in } \mathrm{kg} / \mathrm{m}^{3} \\
& \begin{array}{l}
\mathrm{V}_{\mathrm{fs}}=\text { the liquid draining velocity in } \\
\mathrm{m} / \mathrm{s} .
\end{array} \\
& \rho_{\mathrm{g}}=\text { the vapor density in } \mathrm{kg} / \mathrm{m}^{3} \\
& \mathrm{~g}=\text { the acceleration of gravity in } \mathrm{m} / \mathrm{s}^{2} \\
& \mathrm{D}=\text { the pipe diameter in m } \\
& \theta=\text { the inclination of the pipe from the } \\
& \text { horizontal }
\end{aligned}
$$




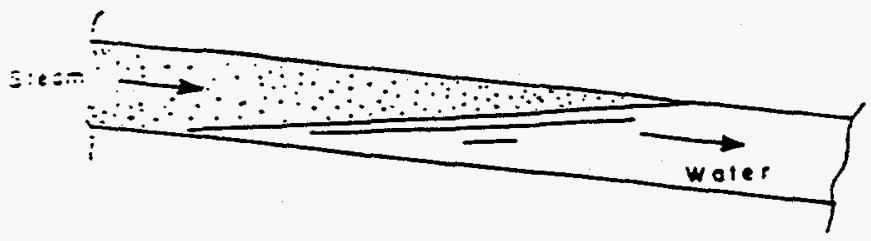

a.

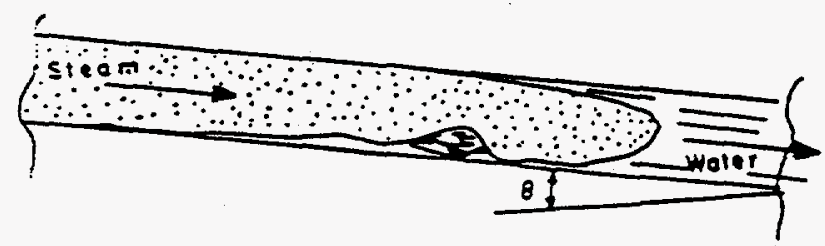

b.

Figure 2-3. The stratified to slug transition in a draining pipe. (a) Low velocity drainage. $\mathrm{Fr}_{\mathrm{d}}<44$. (b) High velocity drainage.

$\mathrm{Fr}_{\mathrm{d}}>44$, Equation (2-3), Reference (14).

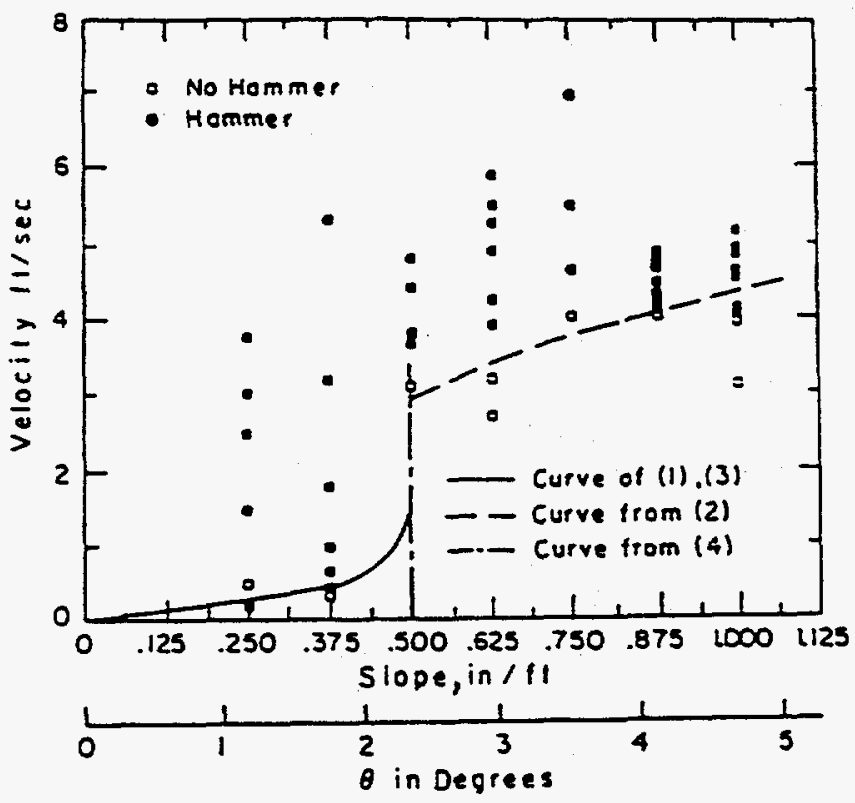

Figure 2-4 The stability map for a draining pipe with inclination angle from the horizontal as the primary variable. The pipe diameter in these experiments in $5 \mathrm{~cm}$. Reference (14). 


\subsection{Column separation and rejoining and refilling voided pipes. This} process arises in a variety of system maneuvers and operational mishaps. In essence, this kind of water hammer is due to the rapid condensation of a bubble which is formed and trapped at the closed end of a pipe.

Reference (2) describes this process in some detail. Rapid valve action is not the only cause, however. Any blind ended pipe which is originally steam-filled and is subsequently filled rapidly with cold water can experience this kind of water hammer too. The filling process itself traps the steam in the blind-ended pipe. This might cause steam to condense rapidly leading to a low, local pressure. This will cause water to flow into the cavity so rapidly that a water hammer will result just when the filling process is complete. Horizontal, vertical and inclined pipes are all prone to this kind of water hammer. This kind of water hammer can usually be eliminated by not maneuvering the system too rapidly. The stable, stratified pool of water is then not disturbed.

The next two mechanisms, pump start and passive water hammer, do not apply to the primary or high pressure sides of the secondary though they have occurred in other reactor systems. At this time, the details in the design of the advanced reactor systems are sufficiently indistinct so that a description of these water hammers is included here in case some safety related system is designed so that it can experience one of these. Auxiliary systems in the advanced reactors can experience these water hammers just as they can in existing LWR's.

2.6 Pump start: Water hammers can occur if a pump is turned on and fills a pipe too quickly. Containment spray systems, for instance, draw water from a sump and pump it to a high place in the containment where it is then sprayed into the containment to cool down its contents. If the check valve, which is normally in the line just after the pump, leaks, that line can, over time, drain. When the pump is turned on, the flow resistance of the air and resulting back pressure are very small. The velocity acquired by the water can be so great, that when the water hits the spray head, an unacceptable hydraulic load or water hammer can occur.

This problem is eliminated by using a keep-full system on the spray line. A keep full system is a small (pony) motor and pump used to circulate a small flow of water through the core spray system all the time. This keeps it full whether the check valve is leaking or not. This should not be a problem for the safety systems of an advanced reactor because there are not any active pumps to refill the system too rapidly. Other intermittently-operated, non-safety systems on the reactor might use pumps and have problems like this, however.

2.7 Passive water hammer: This kind of water hammer has been observed to occur in feed water heater drains and has, perhaps, occurred in other systems too. In essence it arises when a heater drain, which is full of cold condensate, is opened in the course of restarting the plant. When this is done, the flow control or throttle valve between the heater drain line and the condenser must be opened to let the condensate out. To start with, the condensate is cold and no flashing occurs. When hot condensate fresh from the feedwater heater arrives at the throttle valve, however, flashing takes place, the pressure drop suddenly increases and the flow rate is reduced. This flow reduction causes a water hammer. References (8 and 9).

This transient can be accommodated by draining all the cold condensate out of the heater drain line slowly enough so that, even if the flow is stopped completely, the resulting pressure rise is acceptable. In any case, suitable starting procedures should be sufficient to eliminate this kind of water hammer as a problem. For the advanced reactors, this kind of water hammer should never be a problem in the primary, either, as in the refilling processes, the flow goes from a cold reservoir to a hot system and such a water hammer is impossible. 
2.8 Chugging: When steam is discharged into a pool of cold water at a sufficiently low mass velocity, a type of water hammer called chugging occurs. This has occurred in BWR pressure suppression pools and can occur in other systems as well. Early experiments which were called "water cannons", are reported in Reference (4). Chugging is essentially unavoidable when steam is vented into cold water unless measures are taken to control it. The mechanism is as follows.

As the mass velocity of steam discharged from a vent in down flow into a pool of cold liquid decreases, the condensation process removes steam more rapidly than it is provided. This reduces the steam pressure in the vent pipe which sucks up the water from the pool. The cold water that is exposed by this flow condenses still more steam and soon a rapid reduction of the pressure in the vent pipe takes place. The pressure typically drops to a value that is close to the saturation pressure for the pool. This causes the water velocity in the vent to rise to a high enough value to cause a water hammer as soon as a valve or bend is impacted by the column of water advancing up the vent. The resulting hydraulic forces are usually unacceptable.

The accepted way of eliminating chugging is to put a vacuum breaker in the vent line. This breaks the vacuum before the water has risen far enough in the line to do any damage. Another way to handle the problem is to add a non-condensable gas to the steam. This puts a diffusion resistance in series with the condensing heat transfer resistance, thereby reducing the condensing rate, and also diminishes the sonic velocity in the flow going up the vent. The lowered condensing rate reduces the velocity, while the diminished sonic velocity reduces any water hammer pressure rise. One percent air in the steam is sufficient to eliminate these water hammers (10).

\subsection{Pipe clearing transients:}

References (11) and (12) describe a variety of pipe clearing transients. The pipe clearing process consists of blowing a plug or pool of liquid out of a pipe or fitting. As long as the plug of liquid remains coherent, the forces exerted by this liquid as it travels around the pipe can be considerable. Because these large forces are undesirable, the steam systems should be designed so that pools of condensate don't form. If this is impossible, as it often is, the valve should be opened gradually enough so that any liquid trapped in the pipe is cleared slowly and the peak forces the pipe experiences are acceptable. Perhaps a capillary bypass should be used.

References (11) and (12) describe in detail how one might do this.

Of necessity, piping systems often have low points or loop seals in them whether the designers really want them or not. Even if they cannot be eliminated, the piping system should be run in such a way that the resulting clearing can be accommodated.

Sometimes the pool forms where it is not expected as a result of the condensation of steam escaping though a leaky control or check valve. Whether this possibility has been considered in the design and operation of the piping system, usually isn't clear so that important vent and drain lines should probably be operated with this possibility in mind. 
3.0 Estimating the severity and duration of a steam bubble collapse induced water hammer (SBCIWH). For screening purposes a precise description of the pressure-time relation imposed on a piping system due to SBCIWH is not needed and is, in any case, unattainable. Rather, a simplified model that captures the important physics and gives a reasonable, but generally conservative answer, should be sufficient. That is the goal we have adopted here. We start with the Jukowski equation.

$$
\Delta P=K \rho_{f} C(\Delta V)
$$

Recommendations for calculating each term in this equation will now be made for the case of a transition from a stratified or annular flow into slug flow in a horizontal pipe. A description of how this equation is to be used to estimate the water hammer pressure surge and its duration for several other systems will also be made as appropriate.

Let's start with a horizontal steamfilled pipe receiving a flow of cold water which is transitioning to slug flow. This is the state illustrated in the cartoon which is shown in Figure (2-1). Let us further idealize this process by saying the void fraction in the region in which both phases are present is $50 \%$. (This assumption turns out to be almost the worst condition and, for our purposes, makes our analysis particularly simple). The worst way these phases can be arranged is to have a steam bubble trapped between a cold liquid column and a slug of cold liquid. Figure 3-1 shows this. [This figure is really an idealization of Figure 21(C)]. In order to determine the peak pressure attained when the trapped steam bubble is completely condensed, we must determine the velocity attained by the slug due to the condensation of the steam bubble. 


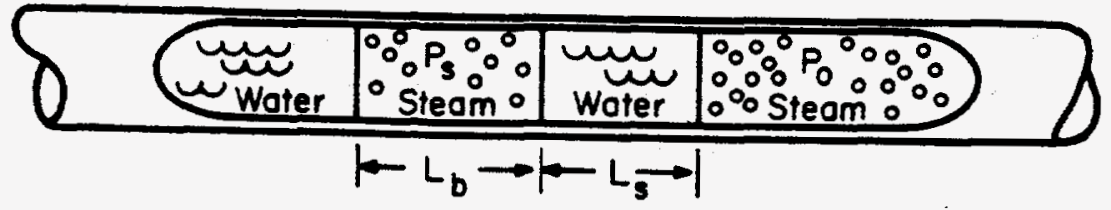

Figure 3-1. A bubble trapped between a column of cold water and a slug of liquid. 
Either the slug inertia or the wall shear stress can limit this velocity. If the inertia

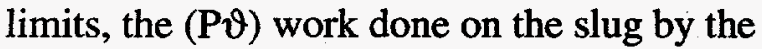
steam advancing into the pipe is equal to the increase in kinetic energy of the slug. That is,

$$
\left(P_{o}-P_{s}\right) \vartheta_{b}=1 / 2 \mathrm{~m} V_{s}^{2} \text {. }
$$

which becomes

$$
\left(\mathrm{P}_{\mathrm{o}}-\mathrm{P}_{\mathrm{s}}\right) \frac{\pi D^{2} L_{b}}{4}=\frac{1}{2} \rho_{f}\left(\frac{\pi D^{2} L_{s}}{4}\right) V_{s}^{2}
$$

In these equations:

$$
\begin{aligned}
& \mathrm{P}_{\mathrm{O}}=\text { The existing pressure in the pipe } \\
& \text { in Pa. } \\
& \begin{aligned}
& \mathrm{P}_{\mathrm{S}}= \text { The saturation pressure of } \\
& \text { the water in the pipe in } \mathrm{Pa} .
\end{aligned} \\
& \mathrm{m}=\text { The mass of water trapped in the } \\
& \text { slug in } \mathrm{kg} \text {. } \\
& \mathrm{V}_{\mathrm{s}}=\text { The velocity of the slug in } \mathrm{m} / \mathrm{s} . \\
& \vartheta=\text { The volume of the bubble in } \mathrm{m}^{3} \\
& \mathrm{D}=\text { The pipe diameter in } \mathrm{m} . \\
& \mathrm{L}_{\mathrm{b}}=\text { The length of the bubble in } \mathrm{m} . \\
& \mathrm{L}_{\mathrm{s}}=\text { The length of the slug in } \mathrm{m} .
\end{aligned}
$$

Generally $\mathrm{P}_{\mathrm{S}} \ll \mathrm{P}_{\mathrm{O}}$ and as the void fraction is assumed to be $50 \%, \mathrm{~L}_{b}=\mathrm{L}_{\mathrm{s}}$ so equation (3-1) becomes,

$$
\mathrm{V}_{\mathrm{s}}=\left(\frac{2 P_{o}}{\rho_{f}}\right)^{\frac{1}{2}}
$$

Alternatively, wall friction could limit the slug velocity. Doing a force balance on the slug we obtain,

$$
\mathrm{V}_{\mathrm{s}}=\left[\frac{2 P_{o}}{f\left(\frac{L_{s}}{D}\right) \rho_{f}}\right]^{\frac{1}{2}}
$$

Where, $\mathrm{f}=$ the friction factor, which we will assume is a constant equal to 0.02 . This is good enough for these purposes. Figure 3-2 shows these limits and the actual velocity-time curve. The smallest velocity from either equation (3-2) or (3-3) is the one to use. This velocity is actually the $(\Delta \mathrm{V})$, the extinguished velocity, appearing in equation (1-1). The initial filling velocity, compared to the slug velocity, is always very small.

Let us now turn to the velocity of sound in the column of cold water, " $\mathrm{C}$ " in equation (1-1). In general, the velocity of sound in a pipe is primarily a function of the fluid temperature. Figure (A-1) in Appendix A is reproduced from Reference (2) and gives the velocity of sound in water, steam and homogeneous steam-water mixtures. If the fluid is completely liquid water which is confined to a pipe, the elasticity of the pipe gives rise to an approximately $10 \%$ reduction in the effective sound velocity (1). For this example, we are going to assume the pipe contains pure, cold liquid water. In fact, however, in none of the experiments that have been run at M.I.T. have we ever found the velocity of sound in the water in a pipe to be as high as that given as Figure $(\mathrm{A}-1 \mathrm{a})$ implies. Apparently, because of the way we ran the experiments, a few bubbles were always present. A tiny void fraction can reduce the effective sonic velocity in water by a huge factor. Instead of a sonic velocity of about $1400 \mathrm{~m} / \mathrm{s}$ (or $4800 \mathrm{ft} / \mathrm{s}$ ) we typically observed sonic velocities of about $2000 \mathrm{ft} / \mathrm{s}$. (Two phase mixtures with void fractions of several percent and at low pressure can display sonic velocities as low as $30 \mathrm{ft} / \mathrm{s}$ ). For practical calculation, treating the sonic velocity as a parameter which has an uncertainty range makes the most sense. When the comparison of these recommendations with some experiments is made in Appendix A, the range of sonic velocities the user should exercise in his analysis will become clearer. Though the sonic velocity and thus the peak pressure is quite uncertain, the impulse which acts on the pipes is not, so the resulting deflection of the pipes due to the water hammer can usually be calculated with fair accuracy. (Usually the natural frequency of vibration of the piping systems lies between 4 and $40 \mathrm{~Hz}$ and the impulse rather than the peak pressure dominates the maximum pipe 


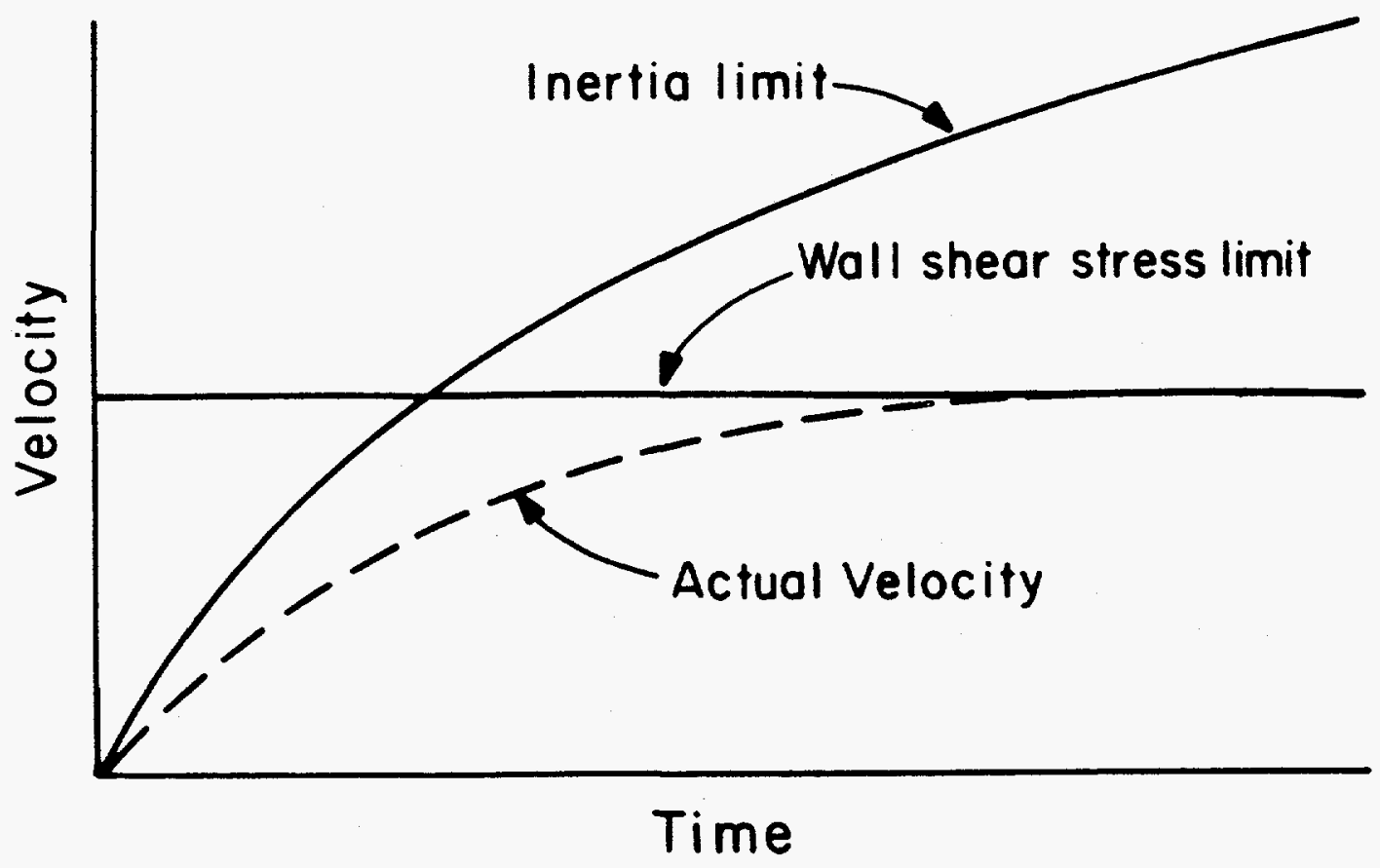

Figure 3-2. The variation of the velocity of the slug as a function of time showing the inertia limit and the wall shear stress limits as well as the actual velocity. 
deflection). The impulse for a system filled with cold water acts normally for a time interval that is considerably less than the period of the pipe and the resulting maximum deflection is usually less than that which would be obtained if the peak force acts steadily.

The coefficient " $\mathrm{K}$ " in equation (1-1) reflects, in part, the geometry of the system. If, as is the case illustrated in Figure 3-1, the slug hits a column of water, the coefficient is:

$$
\mathrm{K}=0.5 \text {, }
$$

while, if it hits a solid metal end like a closed valve, the coefficient is:

$$
\mathrm{K}=1.0 \text {. }
$$

The difference in these two cases is due to the fact that there are two pressure waves formed if the slug hits a column of water and only one if it hits a solid end. If all the slug kinetic energy is contained in a single pressure wave, its amplitude is higher.

The impulse that is imparted by the slug to the column of water in the pipe is always that which is sufficient to stop the slug.

In general:

$$
I=\int \mathrm{Fdt}
$$

which becomes

$$
=\mathrm{m}_{\text {slug }}\left(\mathrm{V}_{1}-\mathrm{O}\right) \text {. }
$$

The force in equation (3-5) acts over the period of time it takes the pressure wave to make it from the impact surface to the free surface and back. That is, for Figure (3-1), the impulse is,

$$
\mathrm{I}=(\mathrm{PA}) \frac{\left(2 L_{s}\right)}{C}
$$

In equation (3-5):

$$
\begin{aligned}
& \mathrm{I}=\text { The impulse needed to stop the slug } \\
& \text { in } \mathrm{kg} \mathrm{m} / \mathrm{s}
\end{aligned}
$$

$$
\mathrm{m}_{\text {slug }}=\text { The mass of the slug } \mathrm{kg}
$$

$$
\begin{aligned}
& F=\text { The force exerted by the slug, } N \\
& t=\text { The time over which the force acts, } \\
& \text { S. } \\
& \begin{array}{l}
P=\text { Pressure exerted to stop the slug, } \\
\text { Pa }
\end{array}
\end{aligned}
$$

$$
A=\text { Area of the pipe, } \mathrm{m}^{2}
$$

The impulse imparts momentum to the piping system which then deflects an amount related to its mass and stiffness.

Before dropping this topic, this theory should be compared to some data. This comparison is shown in Appendix A as well as some example calculations using these methods.

The primary cause of the scatter which is evident in the data shown in Appendix A, is, I believe, due to the uncertainty in the value for the velocity of sound that is chosen. Very little vapor in the liquid hugely decreases the " $C$ " and thus the peak pressure. The amount of vapor in the system is not well controlled in these experiments and is certainly not in the systems of interest.

\subsection{Pipe clearing transient description:} One process, that is perhaps better described as a severe fluid transient rather than as a water hammer, is the pipe clearing transient. References (11) and (12) describe the calculation of this transient completely and everything in this section is drawn from those works. The problem is to determine the forcetime relation resulting when a pool or plug of water trapped in a pipe upstream of a bend (for instance) impacts the bend when the pipe is cleared by steam (or gas for that matter) when it is suddenly admitted to the pipe.

Figure (4-1a) shows such a pool in a pipe while Figure (4-1b) shows how it is idealized into a plug. Figure (4-2) shows a large number of peak force data points taken for a variety of initial void fractions and clearing velocities. Below this figure is a series of cartoons which show several of the forcetime traces measured at the bend. The 
parameter is the liquid fraction trapped in the loop seal upstream from the bend.

Until the liquid fraction exceeds 0.2 , or

$$
\alpha<0.8
$$

in the pool, no measurable force due to clearing the liquid is observed. All the data obtained in these experiments has been correlated using a simple plug flow model. That model is as follows Figure (4-1). The peak force is calculated assuming the liquid is a coherent cylindrical plug of the same volume as the original pool. This plug impacts the bend at the nominal velocity. The idealized peak force then is

$$
\mathrm{F}=\rho_{f} V_{n}^{2} A_{x}
$$

In equation (4-2),

$$
\begin{aligned}
& F=\text { The force exerted at the bend in } N \\
& \rho_{f}=\text { The liquid density in } \mathrm{kg} / \mathrm{m}^{3} \\
& \mathrm{~V}_{\mathrm{n}}=\text { The nominal velocity of the } \\
& \text { driving fluid (gas or steam) in } \mathrm{m} / \mathrm{s} \\
& \mathrm{A}_{\mathrm{x}}=\text { The cross section area of the pipe } \\
& \text { in } \mathrm{m}^{2}
\end{aligned}
$$

The idealized force is used to nondimensionalize the actual force trace.

$$
\mathrm{F}^{*}=\frac{F_{\max }}{\delta_{f} V_{n}^{2} A_{x}}
$$

This peak force is correlated on Figure (4-3) as a function of dimensionless distance downstream of the pool. The dimensionless slug length, $\mathrm{L}_{\mathrm{s}}$, is defined as

$$
\mathrm{L}_{\mathrm{s}}=\frac{\vartheta_{s}}{A_{x}} .
$$

In equation (4-4),

$$
\begin{gathered}
\vartheta_{s}=\text { The volume of the liquid slug } \\
\text { trapped, in } \mathrm{m}^{3}
\end{gathered}
$$

The dimensionless distance is an important parameter because it reflects how much liquid has been left behind as the slug advances down the pipe. After it has gone about 5 slug lengths, the slug becomes an incoherent mass of spray.

This is to be expected as the nose of the slug flow bubble advances into the slug at a velocity which is about $20 \%$ greater than the flow velocity in the pipe. This increase in velocity for the nose of the bubble reflects, more than anything else, the turbulent velocity profile in the pipe.

The nominal time it takes the slug to pass through the bend is,

$$
\mathrm{t}_{\mathrm{n}}=\frac{\vartheta_{s}}{V_{n} A_{x}}
$$

In equation (4-5) where,

$$
t_{n}=\text { the nominal time it takes a slug to }
$$
pass through the bend in $\mathrm{s}$.

The dimensionless impulse shown in Figure (4-4) is then,

$$
I^{*}=\frac{\int F d t}{\rho V_{n}^{2} A_{x} t_{n}}
$$

in which the dimensionless time is

$$
\mathrm{t}^{*}=\frac{t}{t_{n}}
$$

In these equations,

$$
\begin{aligned}
& I^{*}=\text { The dimensionless impulse } \\
& \mathbf{t}^{*}=\text { The dimensionless time the impulse } \\
& \text { acts }
\end{aligned}
$$

The duration and magnitude of the force and the impulse can be obtained from Figures (4-3) and (4-4). 

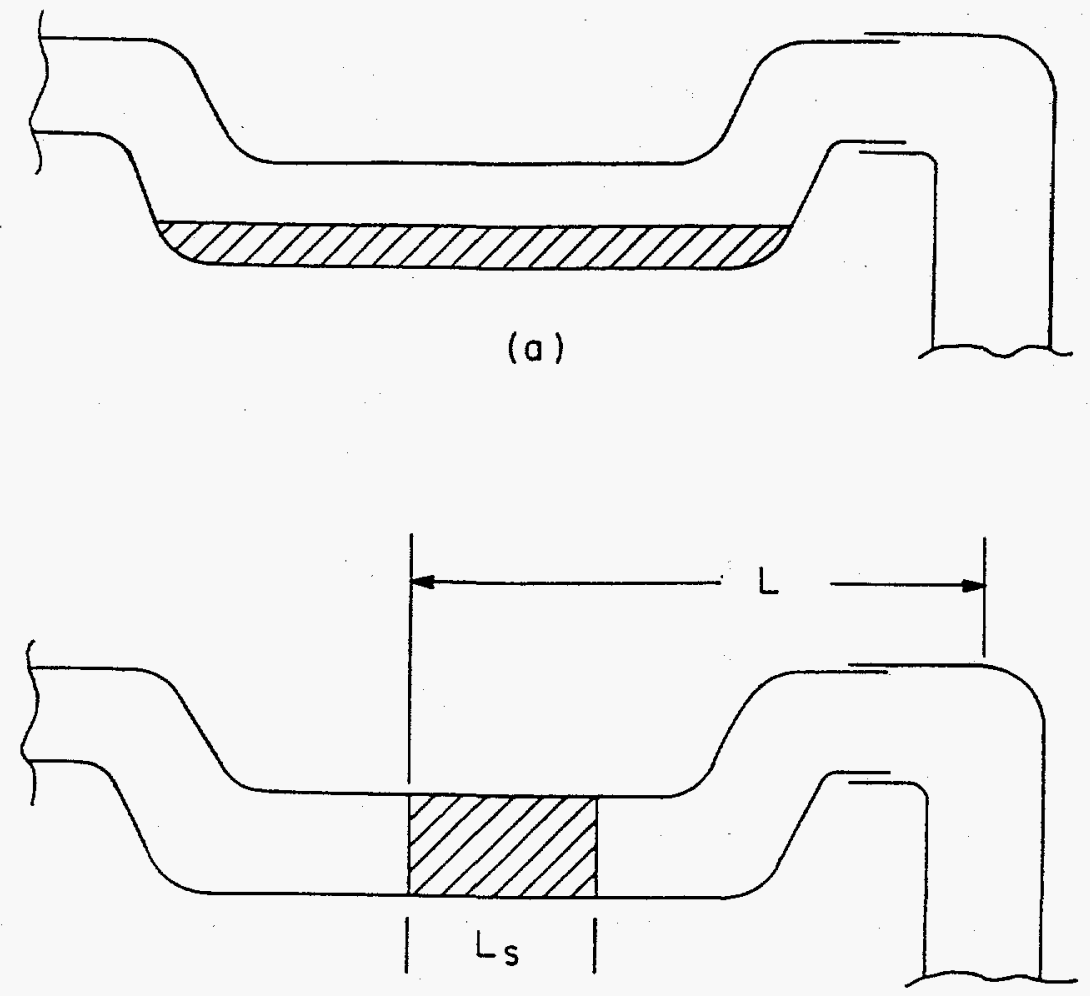

(b)

Figure 4-1. (a) The actual configuration of water trapped in a low point in a pipe and (b) the assumed configuration when the pipe is cleared by a flow of steam or air from the left. References (11) and (12). 


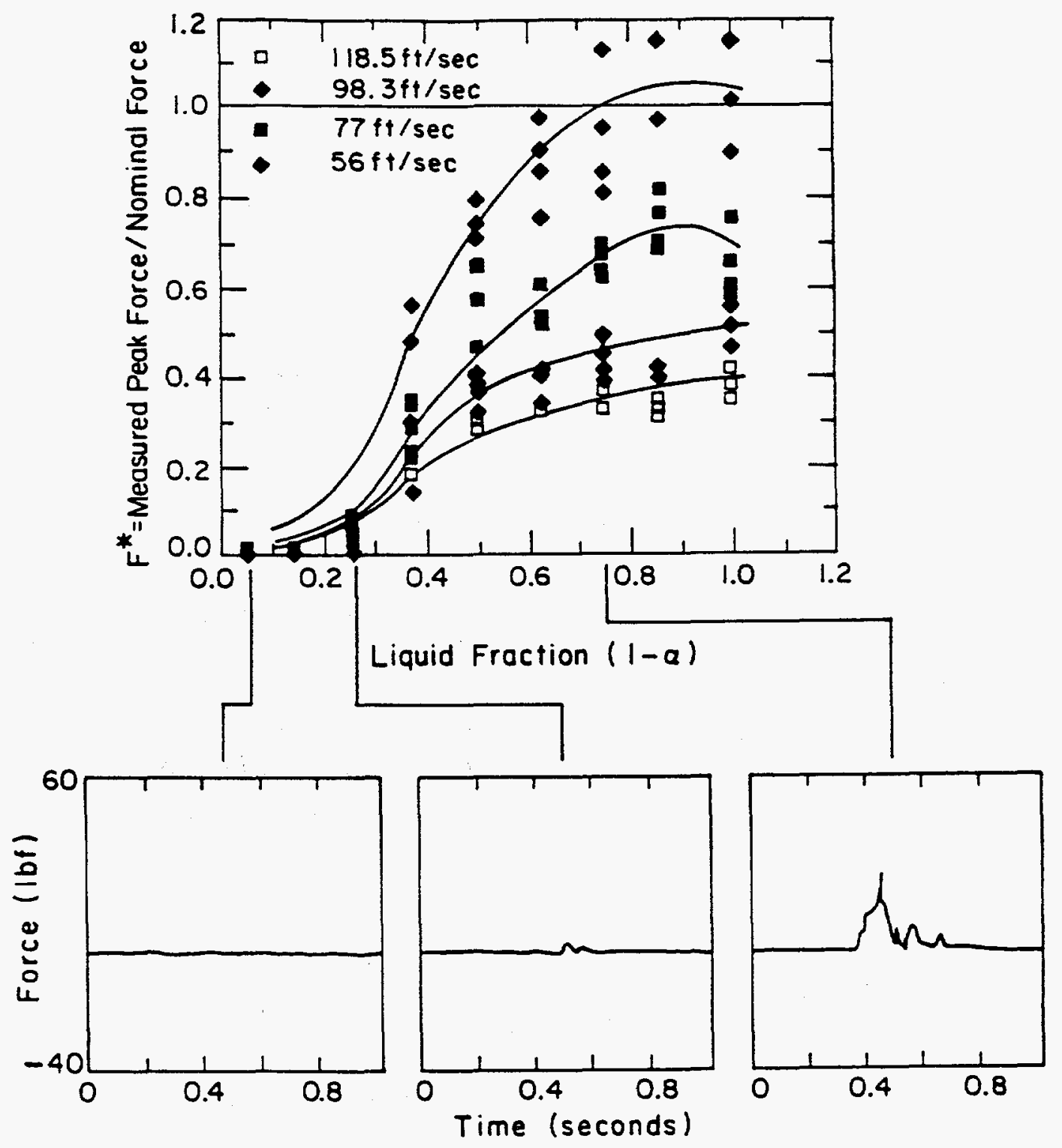

Figure 4-2. Force-time data from the pipe clearing experiments of Reference (11). The top figure is a summary of the peak forces measured. The cartoons at the bottom are samples of the measured force-time traces for selected initial liquid fractions upstream of the force transducer. 


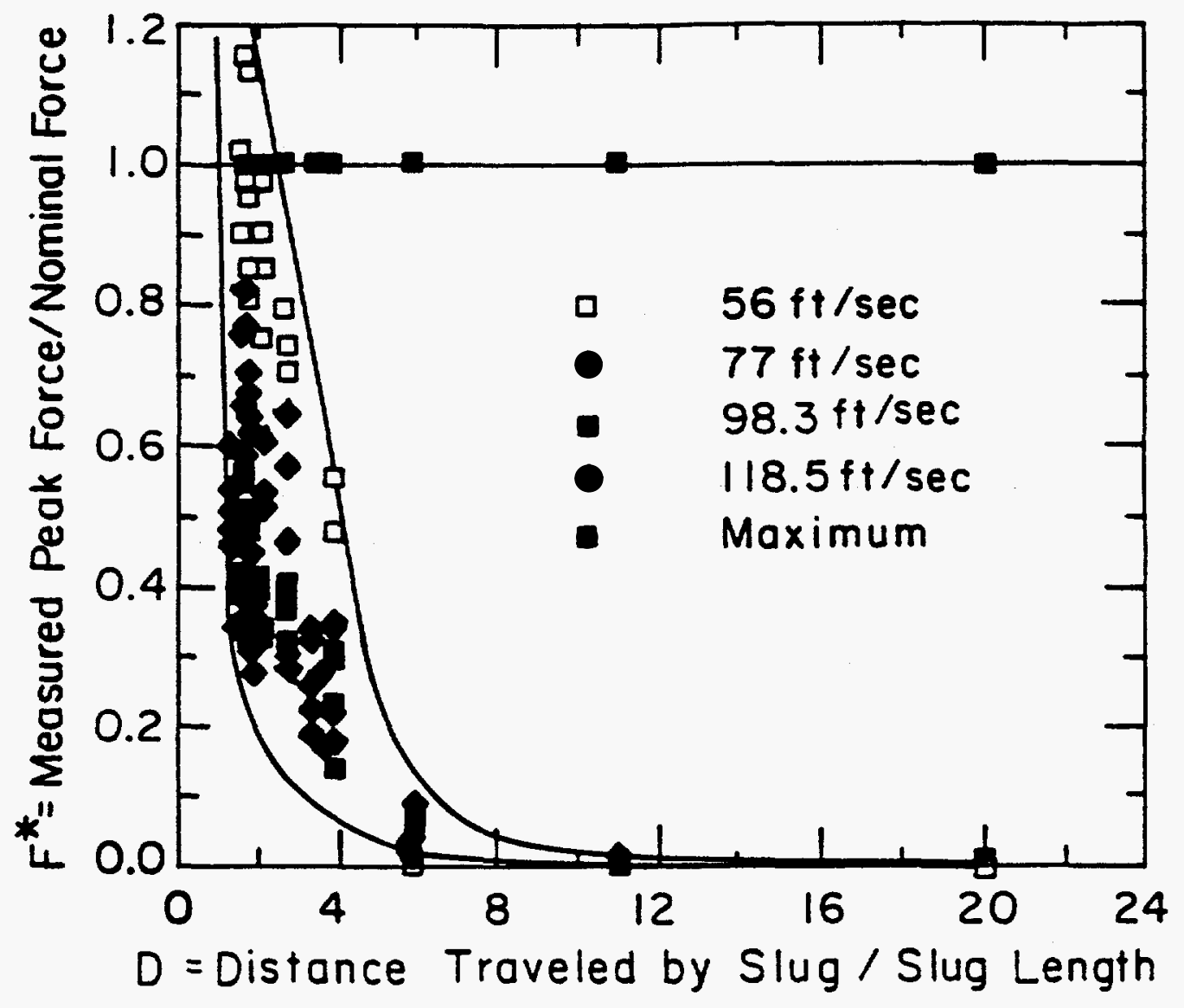

Figure 4-3. The decay of the peak force as a function of the distance a slug travels. If enough straight pipe is provided after the trap or loop seal, the clearing force downstream can be reduced to manageable values. Reference (11). 


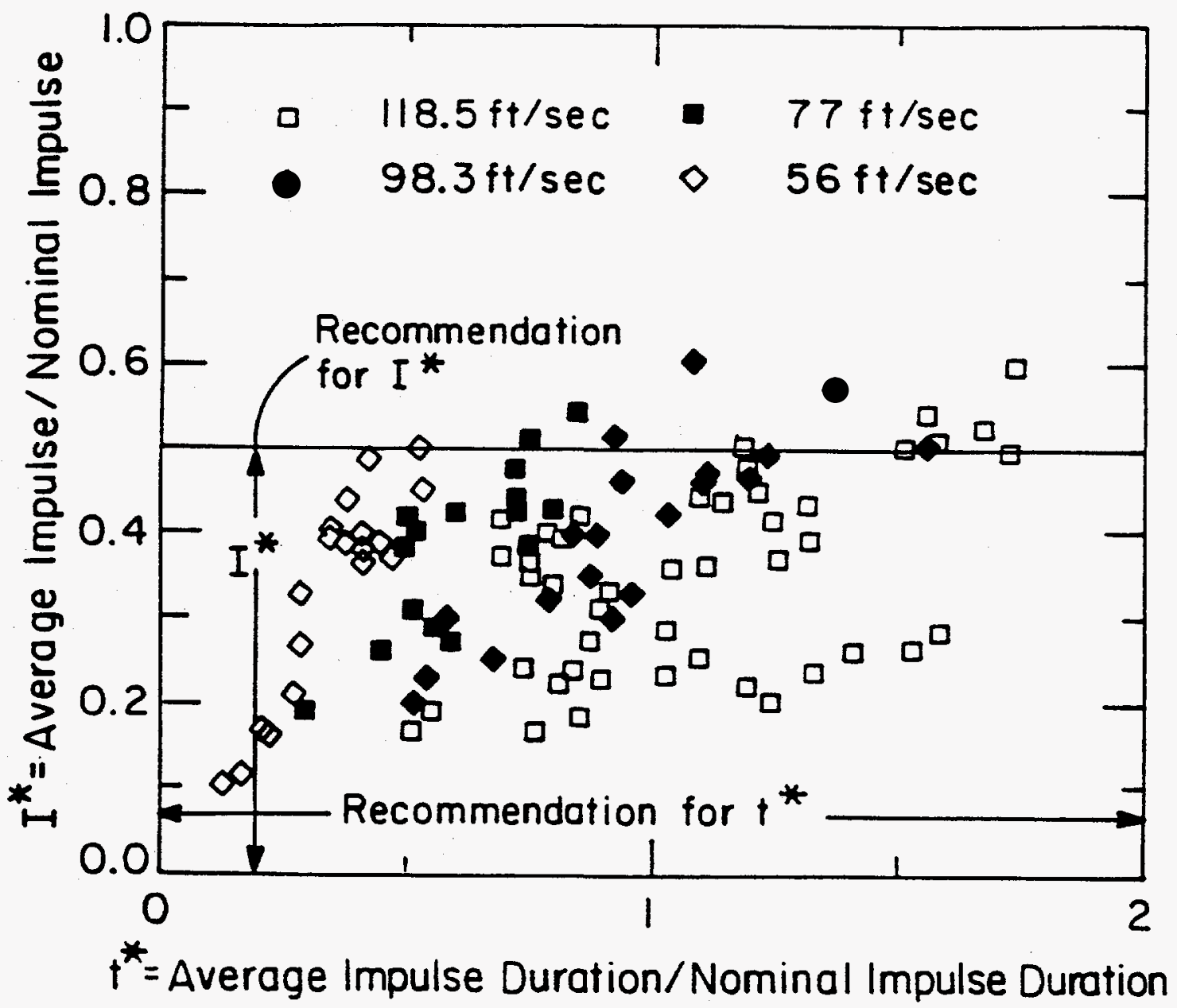

Figure 4-4. Impulse durations for pipe clearing experiment. Reference (11). 
5.0 Experience in existing LWR's: Before going to the specific example, which is based on a proposed advanced light water reactor design, it is appropriate to review and summarize what has been learned on existing BWR's and PWR's. Virtually all the water hammers observed in existing LWR's have occurred in the auxiliary systems, not the primary. Most of these can be traced to one of two overriding causes:

1) Inexperienced operators because the plant is new so that the procedures that might cause a steam bubble collapse induced water hammer have not all been identified or,

2) A piece of equipment like a check valve, fails and starts to leak.

This causes steam to be present where only water should be or perhaps causes condensate to collect in a pipe that should contain only steam. Reference (3) classifies the water hammers in such a way that the auxiliary systems that are most prone to water hammers can be identified and appropriate design and operating precautions taken. The details on the precautions provided in Reference (3), will not be duplicated here. We will focus only on the problems that are unique to the advanced reactors because these are the only designs in which water hammers might occur in the primary.

Tables (5-1) and (5-2) from Reference (3) summarize the experience utilities have had with water hammers obtained on existing LWR's. These two tables are inserted here as a reminder that a plant can experience water hammers in the auxiliary systems as well as primary and some of these water hammers may have safety implications. Steam bubble collapse induced water hammers are not the only possibilities. References (3) and (15) describe some other possibilities as well. Most of the information in Reference (3) was provided in licensee event reports submitted to the NRC in the course of operating these reactors. Even though this data is for existing LWR's, it can tell us a lot.

Feed water systems and steam generator nozzles are particularly prone to water hammers. This is because they are the parts of the system which would normally have cold water in them and yet are at high pressure. During certain transients, however, they may also have steam in them. The combination of cold water and steam is the most common precursor of a steam bubble collapse induced water hammer. Their presence is, indeed, essential if a SBCIWH is to occur at all. Components in the advanced reactors that usually have cold water but may have steam in them are the first places to look for water hammer problems.

The feature that makes the advanced light water reactors different from existing LWR's is that they are designed to be blowndown and then refilled with cold water using natural circulation. The automatic depressurization system (ADS) and the direct vessel injection systems (DVI) which accomplish these processes are unique to the advanced reactors and thus are the likely places to find any new problems. The ADS would most likely have a problem during blowdown while the DVI system would be most likely to have one during refill. The core makeup tanks are new as well so their performance must also be examined. Most of the other components in the advanced LWR's are also in existing LWR's and are thus less likely to have problems. We now know how to operate these systems.

\subsection{Screening an unbuilt system for} water hammers: The specific example chosen to illustrate the suggested screening procedures is based on the AP600 conceptual design and is illustrated in Figure 5-3. (This figure was provided to the NRC by

Westinghouse). It is not a final design and is certainly not complete. Many details such as valves and their locations, stress-relieving loops, pipe inclinations, instruments, drains and vents and so forth are all omitted from this picture. None-the-less, this figure is useful for identifying the places where problems might arise and suggests what the problem might be. Only a detailed examination based on piping isometrics, the study of component details like valve geometries and a knowledge of the states passed through from the computer simulations of the transients will allow one to see if there is actually a SBCIWH problem. 
Looking at Figure (5-1), we can identify a number of places where problems might arise. Table (5-3) gives a key to the numbers on Figure (5-1) along with the section in this report where the likely process leading to a water hammer in the identified component is described.

Not every process mentioned in section (2) of this report is referred to in Table (5-3). This is partly because Figure (5-1) is not complete and some of the drains, vents and other components that are present in the complete plant are missing. The refilling process in short pipes of various orientations and blind-ended components are possible sources of water hammers and should be checked for too. We just don't know where these blind-ended pipes are. In most cases, however, the water hammers that result from the processes not mentioned in Table (5-3) are water hammers best eliminated at the design stage or managed by operational means such as controlled refilling rates. 


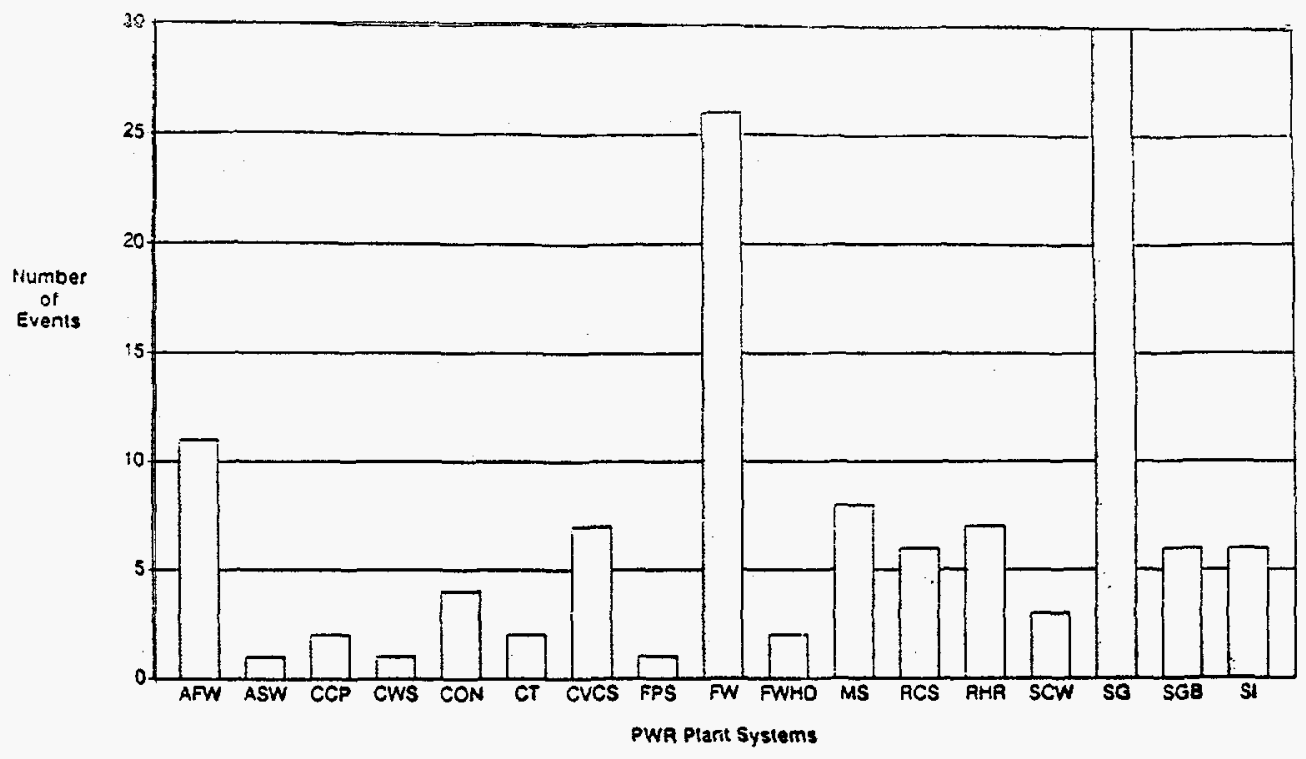

PLANT SYSTEMS

EVENTS

\begin{tabular}{llc}
\hline AFW - Auxiliary Feed Water & 11 \\
ASW - Auxiliary Saltwater & 1 \\
CCP - Component Cooling Water & 2 \\
CCW - Condenser Circulating Water & 1 \\
CON - Condensate System & 4 \\
CT - Containment Spray & 2 \\
CVCS - Chemical \& Volume Control & 7 \\
FPS - Fire Protection & 1 \\
FW - Feedwater System & 27 \\
FWHD - Feedwater Heater Drains & 1 \\
MS - Main Steam & 8 \\
RCS - Reactor Coolam System & 6 \\
RHR - Residual Heat Removal & 7 \\
SCW - Service Cooling Water & 3 \\
SG - Steam Generator & 30 \\
SGB - Steam Generator Blowdown & 6 \\
SI - Safety Injection & 6 \\
\hline TOtal PWR Events & 123 \\
\hline
\end{tabular}

Table 5-1. Water hammer events reported in PWR plant systems. Reference (3). 


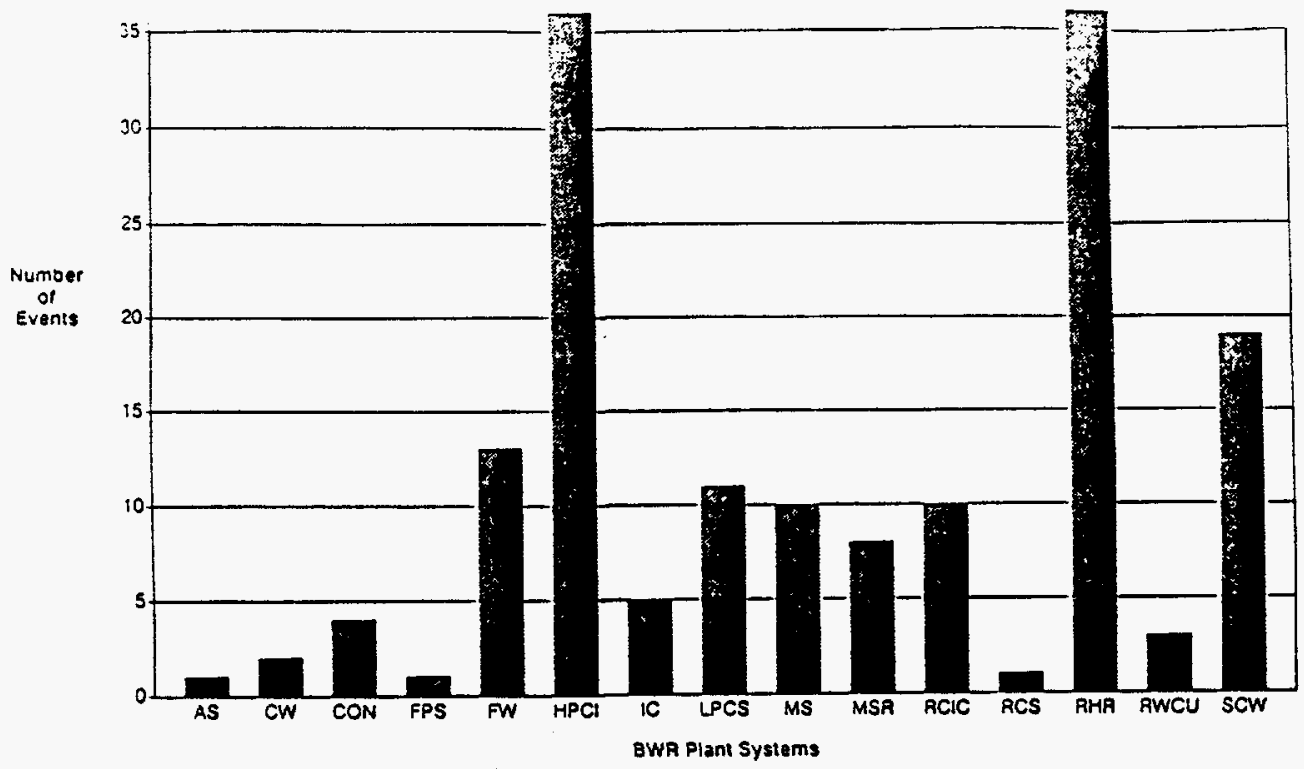

PLANT SYSTEMS

EVENTS

\begin{tabular}{|c|c|c|}
\hline AS & - Auxiliary Steam & 1 \\
\hline CW & - Condenser Circulating Water. & 2 \\
\hline CON & - Condensate System & 4 \\
\hline FPS & - Fire Protection & 1 \\
\hline FW & - Feecwater System & 13 \\
\hline $\mathrm{HPCl}$ & - $\quad$ High Pressure Coolant Injection & 36 \\
\hline IC & - isolation Condenser System & 5 \\
\hline LPCS - & - Low Pressure Coolant Injecsion & 11 \\
\hline MS & - Main Steam & 10 \\
\hline MSR & - Moisture Separaior Reheater & 8 \\
\hline RCIC & - Reactor Core Isolation Cooling & 10 \\
\hline RCS & - Reactor Coolant System & 1 \\
\hline RHR & - $\quad$ Residual Heat Removal & 36 \\
\hline RWCU, & Reactor Water Cleanup & 3 \\
\hline SCW & - Service Cooling Water & 19 \\
\hline \multicolumn{2}{|c|}{ Total BWR Events } & 160 \\
\hline
\end{tabular}

Table 5-2. Water hammer events reported in BWR plant systems. Reference (4). 


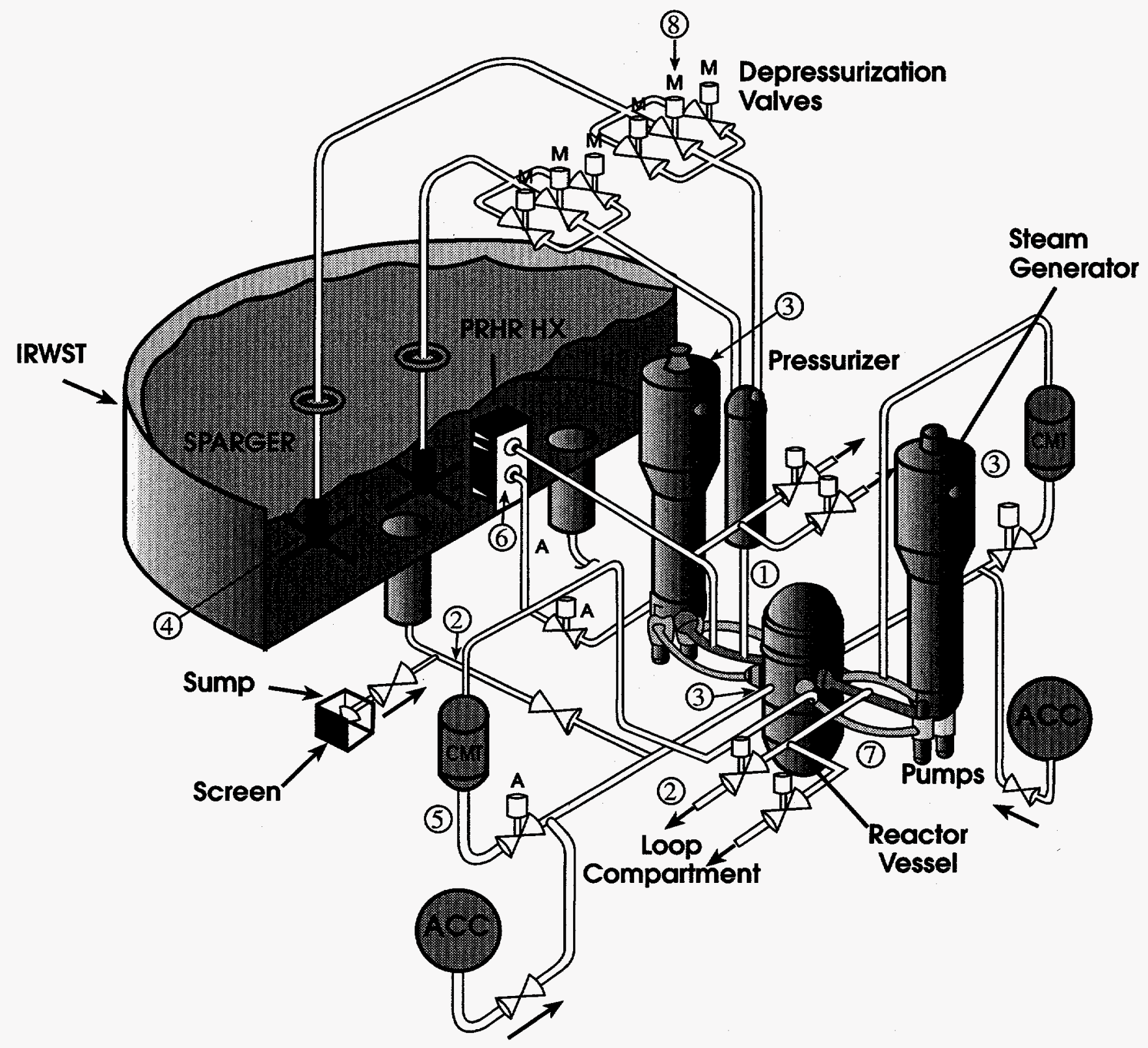

Figure 5-1. Schematic of the AP600 reactor system showing locations that should be checked for steam bubble collapse induced water hammers or severe fluid transients. 
Table 5.3 Components and their Associated Types of Water Hammers or Severe Fluid Transients

Location Location Type of Water Hammer Discussion

Number (Refer to this section)

\begin{tabular}{llll}
\hline 1 & PZR Surge Line & 2.4 & 5.21 \\
2 & DVI Line & $2.1,2.2$ & $5.22,5.29$ \\
3 & DVI Nozzle & $2.1,2.2$ & $5.23,5.29$ \\
4 & ADS1-3 Sparger & 2.8 & 5.24 \\
5 & CMT Drain & $2.1,2.3$ & 5.25 \\
6 & PRHR HX & $2.3,2.4$ & 5.26 \\
7 & Hot Leg/Cold Leg & $2.1,2.2$ & $5.27,5.29$ \\
8 & $\begin{array}{l}\text { ADS1-3Depressurization } \\
\text { Valves }\end{array}$ & 2.9 & 5.28
\end{tabular}




\subsection{Comments on specific components} identified on Figure (5-3): Before proceeding to the screening problem associated with filling a horizontal line, we should take this opportunity to discuss the components and processes appearing in Table (5-3) with the intent of making the screening process easier.

5.21 Surge Line: The geometry of the surge line is almost exactly that studied in Reference (14). The greatest difficulty in calculating whether this is really a problem is probably getting the subcooling correct. SBCIWH would only occur if there is subcooled liquid in the pressurizer at the time when it is drained in such a way that the steam/water interface retreats into the surge line. It isn't obvious in what transient this might occur, but an overcooling transient might do it. Inclining the surge line certainly decreases the likelihood of such a water hammer but even if the line is inclined, there still exists a drainage velocity which can lead to SBCIWH. A very large pressurizer, which has other benefits too, might eliminate this problem.

\subsection{Line: Inclining a nominally} horizontal pipe more than $2.4^{\circ}$ and filling from below are the best ways to avoid this kind of SBCIWH. Under normal operation or for a LOCA anywhere but in the DVI line itself, this line should remain filled with liquid. It is not clear, however, what the temperature of this liquid is. If it is hot enough, it can flash during blowdown and when it refills, the line could pass through a state where it contains cold water and steam. These are the most important ingredients leading to SBCIWH.

If the DVI line is suitably inclined and there is a check valve immediately behind the nozzle leading into the vessel, SBCIWH may never be a problem in this line.

If the DVI line experiences a LOCA, it will certainly drain and refill with cold water but the pressure level at which this happens will be so low that the resulting SBCIWH's are unlikely to further damage the plant. For this component it is important to identify all the transients which lead to voiding in the DVI and make sure any refill with cold water occurs at a low enough pressure such that no damage results.

5.23 DVI Nozzle: The problem here is very similar to the problem in the DVI line. The geometry illustrated in Figure (5-3) is almost identical to the geometry in the Indian Point steam generator which experienced a severe water hammer some years ago. Voiding in the down comer might lead to a similar event here. The procedures and results reported in References (4) and (15) give ample guidance on how to avoid this problem. Most important is to slope the DVI line down from the vessel dropping the DVI line one pipe diameter or more, in less than $24 \mathrm{~L} / \mathrm{D}$ 's.

\subsection{ADS1-3 Sparger: The sparger and} vent line is probably the product of a lot of development work in the past and is likely to work as designed. Here the items to check are: first, does it have a vacuum breaker and second, has the system been tested over the entire range of pressures and vapor flow rates at which it is expected to operate? It is particularly important that the chugging regime be amply tested. The precise conditions leading to chugging are reported in Reference (10). A low enough mass velocity for the steam being released into a cold pool will always lead to chugging and the system must be designed to accommodate it..

\subsection{CMT Drain: Under normal} conditions, the CMT is filled with cold water. It is piped in such a way, however, that it discharges into the DVI line. If the cold water in the CMT is discharged into a partially voided DVI line at high pressure, a serious water hammer can result. I don't know if this combination of states ever arises or even if this is a problem at all but it is worth looking at the computer printouts to see if this kind of water hammer is ever expected to happen.

5.26 PRHR HX: For almost any condition which the PRHR HX is expected to operate, it is vastly over-sized. This means any steam which enters it will soon be condensed and the condensate will acquire lots of subcooling. These are exactly the conditions which lead to SBCIWH, steam and cold water. Depending on the inclination and transient time, the processes in this component could also be like 
draining a line filled with cold water in it (14) or even filling a steam filled vertical pipe with cold water (7). In general, I believe these water hammers, if they occur, will occur with so little subcooling that the pressures will not be damaging. I think though, that the PRHR HX's should be tested over the entire range of flow rates, pressures, and inventories at which it will operate in the plant to insure that we have not missed anything.

When the cold condensate from the PRHR is returned to the primary, the pressure might be high and the condensate very cold so that a SBCIWH could occur. Figure (5-3) does not show how this is done but the same cautions mentioned in the discussion of the DVI line apply here.

5.27 Hot Leg/Cold Leg: The hot or the cold legs can drain and refill at a high enough pressure so that water hammer might be a problem. The screening criteria assembled later in this section address both hot leg/cold leg problem and the DVI problem in considerable detail. I regard these three components as the ones most worthy of our close examination.

\subsection{ADS1-3 Depressurization Valves:}

The depressurization valves illustrated on Figure (5-3) indicate no problems. Apparently no loop seals are present and the lines can be sloped so condensate doesn't collect. On the assumption that this figure is not a complete representation of the actual installation, this potential problem is included here. The issue that needs to be addressed is the pipe clearing problem. Are there any traps or loop seals filled with water upstream of the ADS valves? The water in these traps might lead to unacceptable forces downstream of the ADS valves when the pipe is cleared.

As it is easier to seal a valve which is backed up with cold water than one backed up with steam, I expect the valves are actually designed with a trap upstream which fills with condensate under normal operation. When the valve is opened, a slug of cold water is released into the discharge pipe and possibly causes a severe fluid transient. Section (2-9) and references (10) and (11) will provide all the information needed to check the adequacy of these designs. Programming the valve opening correctly, if there is a loop seal upstream eliminates this problem.

\subsection{Discussion of the screening} criteria used for SBCIWH due to the stratified/slug transition. By far the most persistent steam bubble collapse induced water hammer problem is filling a steam filled pipe with cold water. A number of components are potentially prone to this problem. At the very least, the DVI line, the hot legs and the cold legs are possible problem areas. A number of conditions need to be met if such a process is to lead to a damaging water hammer. These are listed and described below. Most of them can be gleaned from reference (4) or the thesis that reference (4) is based on. First, let us look at the geometric conditions.

The first condition is that the pipe be long enough. For a steam bubble collapse induced water hammer to arise, the horizontal pipe L/D must be more than 24. Long horizontal pipes with $\mathrm{L} / \mathrm{D}>24$, are all prone to this problem. Short pipes don't provide enough inter-facial condensation area to give rise to a sufficiently vigorous steam counter flow to force a transition to slug flow. This means that no bubble is trapped and no SBCIWH water hammer occurs. Conservatively, water hammer will occur if,

$$
\mathrm{L} / \mathrm{D}>24 \text {. }
$$

The $L / D$ in equation (5-1) is the number of L/D's of horizontal pipe between components. Bends, in a horizontal plane, don't count as a component in this case.

A special combination of fluid thermodynamic states, and conditions must prevail if water hammer is to occur. The most important of these is the sub-cooling must be large enough. Precisely how large is unacceptable, is not clear at this time, but looking at a lot of water hammer data, subcoolings less than $20^{\circ} \mathrm{C}$ do not often lead to serious steam bubble collapse induced water hammers. Many subcoolings greater than this 
don't lead to SBCIWH either, but this is a reasonable lower limit for water hammer to occur.

$$
\left(\mathrm{T}_{\mathrm{S}}-\mathrm{T}\right)>20^{\circ} \mathrm{C}
$$

I believe this $20^{\circ}$ really reflects a Jakob number criterion, but we don't have any high pressure data to show exactly what this criterion should be.

For a water hammer to occur the velocity must be low enough so that the pipe doesn't run full. This means the Froude number must be less than 1 . In short, steam bubble collapse induced water hammer occurs when filling a horizontal pipe such that,

$$
\frac{V_{f s}}{\sqrt{g D}}<1
$$

Even though all these conditions are met, a transition to slug flow cannot occur unless the liquid fraction is greater than 0.2. This means water hammer might occur if

$$
\alpha<0.8
$$

The last item that should be considered is the system pressure. If the system pressure is low, the peak water hammer pressure resulting from a transition to slug flow is also low. This is because it is really the system pressure that accelerates the slug of liquid so the maximum velocity to which it can be accelerated is limited by this. Typically, for piping which is designed to an operating pressure of $2000 \mathrm{psi}$, the water hammer pressure attained by a slug of water when the driving pressure is only one atmosphere, does not exceed the 2000 psi operating pressure even if a water hammer occurs. System pressures which are appreciably greater than atmospheric pressure are needed to give water hammer pressures which challenge the system.

Exactly what criterion should be used to select the maximum allowable system pressure for which SBCIWH becomes a problem is not clear. Some possibilities include:
- Yielding the pipe

- Pipe motion

- Valve bonnet failure

- Gasket failure

- Check valve failure

- Pipe motion causing failure in:

- instrument lines

- PRV power lines

- Pneumatic lines

- Hydraulic lines, etc.

For the purposes of this report, we'll assume that the limit is yielding of the pipe which, according to the calculation of Appendix A, occurs when the system pressure is about 150 psia. Let us say that SBCIWH can be a problem if,

$$
P_{\text {system }}>P_{\text {failure limit }}
$$

$P_{\text {failure limit }}$ is evaluated and the methods illustrated in Appendix A using the most limiting condition out of the list of possible failures given above. This list is not necessarily complete and should perhaps be augmented to include additional possibilities.

\subsection{Using these criteria to screen a} design: There are still some value judgments and assumptions that have to be made in order to use these criteria to screen a design. This section will give guidance on how this is to be done.

A finite number of transients will be investigated using some version of RELAP. Most of the components we are concerned with are pipes. The five criteria summarized in section 5.29 have to be interpreted and used in a way which is compatible with the outputs from the RELAP code.

Let us start with the L/D $>24$ condition. However the pipe is nodalized, this should be interpreted as the LD of pipe that is almost horizontal, i.e., the pipe that has a slope that is less than 1 in 24 . Bends in the horizontal plane should be ignored. 
The next condition is the subcooling. It should be more than $20^{\circ} \mathrm{C}$ if there is to be a water hammer. As it is proposed to be used, RELAP does not allow vapor and subcooled liquid to coexist in a single control volume. Therefore, where vapor is present, subcooled liquid will not be found. Though this condition precludes a water hammer, this limitation is not the problem that it appears to be.

The SBCIWH problem only arises during transients, usually refilling transients. In these we can easily imagine cold water advancing into a horizontal pipe. At some time during the transient it is almost certain that one control volume will contain some void while an adjoining control volume will contain subcooled water. It is proposed that a SBCIWH is likely to occur if there is subcooled water in a control volume which is next to one with void in a horizontal pipe. Though many of the details of the SBCIWH process will be missed, the dangerous state and the approximate time and location where SBCIWH might occur will have been identified.

Next we should examine the velocity or Froude number condition. If the cold water is advancing such that the Froude number in the control volume containing the subcooled water is greater than one, the pipe will run full and no water hammer will occur.

The condition that the void fraction be less than 0.8 if water hammer is to occur is harder to apply. My recommendation is to pursue the transient a little longer in time, after which the control volume receiving the cold water will probably show the conditions under which a water hammer will occur. In a word, I suspect failing to meet the void fraction limit on water hammer will not prevent it if the remaining conditions are met. At some time during the refilling process, the conditions for a water hammer will be met and failing to meet the void limit of 0.8 at one moment won't prevent it from occurring later.
Choosing the pressure below which no damage from SBCIWH is to be expected is a little harder. Talking to people who have operated plants, doing some order of magnitude calculations and surveying the licensee event reports is probably necessary to choose a satisfactory cut-off pressure. I believe, however, the system pressure level at which a SBCIWH can be tolerated is appreciably more than one atmosphere and identifying this limit will significantly reduce the amount of screening that needs to be done. It might, for instance turn out that after the 4th stage ADS blows, no damaging water hammer is possible. The pressure might well be too low.

By far, the most common consequence of a water hammer is the damaging of a snubber or pipe hanger. Some of this may be tolerable if the event is rare enough. The potential payoff both in terms of ease of screening an unbuilt system and in laying out clear instructions for the operators makes it worthwhile to answer the question of what pressure level is low enough so that water hammer is not a problem.

If the criteria recommended in this report are followed, I believe many more water hammers will be predicted than will ever be observed in the experiments. Experience may allow us to relax these criteria. Even then, questions as to what constitutes an acceptable water hammer remain to be addressed. To answer the outstanding questions, people in other areas like stress analysis, licensing and operations must be involved in setting the criteria. I believe, however, we now have the tools we need to get a useful answer to the problem of steam bubble collapse induced water hammer in the advanced light water reactors. If it is a concern, I'm confident that the design and operation can be shaped so that it is not a problem. 


\section{Appendix A}

\section{Calculating the allowable system pressure to insure that steam bubble collapse induced water hammer won't lead to failure.}

Introduction: The example calculation given below is provided so that when the failure criterion which determines the limiting water hammer pressure (for which water hammer is not a problem) is identified, it can easily be related to the acceptable system operating pressure. As this is only an example, it should be stressed that the failure modes listed in Section 5-10 should be reviewed for completeness and worked out for several specific systems in order to make sure that the most limiting condition has actually been identified.

For simplicity, we shall assume that the limiting failure mode is yielding of the pipe due to internal pressure. The yield stress, pipe geometry and initial conditions are as follows:

$$
\begin{aligned}
& \text { Pipe Steel } \\
& \begin{array}{ll}
\text { OD }=2^{\prime \prime} \quad \tau_{\mathrm{y}}=50,000 \mathrm{psi} \\
\text { ID }=1.8^{\prime \prime} \\
\mathrm{f}_{\mathrm{w}}=0.02
\end{array}
\end{aligned}
$$

Fluid conditions

$$
\begin{aligned}
& \mathrm{T}_{\mathrm{o}}=60^{\circ} \mathrm{F} \quad \text { so } \mathrm{P}_{\text {sat }} \approx 0 \\
& \mathrm{P}_{\mathrm{o}}=14.7 \mathrm{psia}
\end{aligned}
$$

State of the System:

As idealized in Figure (3-1),

$$
\begin{aligned}
& \mathrm{L}_{\mathrm{S}}=\mathrm{L}_{\mathrm{b}}=48^{\prime \prime} \quad \text { so that, } \\
& \alpha=0.5
\end{aligned}
$$

We must now find the velocity of the slug. Either the inertia or the wall shear stress on the slug determines this limit. The inertia limit is calculated from equation (3-2). It is,

$$
\mathrm{V}_{\mathrm{s}}=\left(\frac{2 P_{o}}{\rho_{f}}\right)^{1 / 2}
$$

while the wall shear stress limit is calculated from equation (3-3).

$$
\mathrm{V}_{\mathrm{s}}=\left[\frac{2 P_{o}}{f\left(L_{s} / D\right) \rho_{f}}\right]^{1 / 2}
$$

The smallest of these governs the resulting velocity.

Equation 3-2 yields a velocity of $46.7 \mathrm{ft} / \mathrm{sec}$ while equation 3-3 yields a velocity of 95.4 $\mathrm{ft} . / \mathrm{sec}$. So inertia governs. See Figure (3-2). The extinguished velocity is then

$$
\Delta \mathrm{V}=46.7 \mathrm{ft} / \mathrm{sec} \text {. }
$$

In order to determine the resulting pressure rise when the slug of water hits the column of water, equation (1-1) must be used.

$$
\Delta \mathrm{P}=\mathrm{K} \rho_{\mathrm{f}} \mathrm{C}(\Delta \mathrm{V})
$$


In this equation $K=1$ for hitting a shut valve or blind-ended pipe; while for hitting a column of water, such as here $\mathrm{K}=0.5$. A velocity of sound " $C$ " is most conveniently obtained from Figure (A-1). For liquid water. Figure (A-1a) is appropriate. (For two phase mixtures, Figure (A-1b) should be used).

In fact, selecting the appropriate sound velocity is the most dubious part of this calculation. Even a tiny void fraction, air or vapor, can greatly reduce " $C$ ". In most experiments we have found the effective velocity of sound in apparently subcooled water is well below that of Figure (A1), typically about half of that given. Small bubbles, most likely consisting of noncondensable gases, always appear to be present. The elasticity of the pipe contributes too, further reducing the pressure rise. (See Reference 1). This reduction is about 10 to $20 \%$ for a steel pipe. For a best estimåte calculation, I'd recommend using half the value given in Figure (A-1a) for subcooled water.

For two phases, the sensitivity of the sonic velocity for a two phase mixture to the void fraction (or equivalently to the vapor to mixture density ratio) is obvious on Figure A-1b.

Returning now to equation 1-1 and using a sonic velocity of $4000 \mathrm{ft} / \mathrm{sec}$ :

$$
\begin{aligned}
\Delta P & =(0.5) \frac{(62.4)(4000)}{(32.2)(144)} \\
& =1256 \mathrm{lb}_{\mathrm{f}} / \mathrm{in}^{2}
\end{aligned}
$$

A usually-conservative, easily-remembered rule of thumb for calculating the pressure rise in a water hammer for cold, gas-bubble-free water in a steel pipe with the end closed is,

$$
\frac{\Delta P}{\Delta V}=\frac{50 p s i}{f t / s e c}
$$

Alternatively, if we use the rule of thumb to calculate the peak water hammer pressure,

$$
\Delta \mathrm{P}=0.5(50)(46.7)
$$

we obtain,

$$
\Delta \mathrm{P}=1167 \mathrm{lb}_{\mathrm{f}} / \mathrm{in}^{2}
$$

Either this or the $1256 \mathrm{lb}_{\mathrm{f}} / \mathrm{in}^{2}$ is the desired answer. 

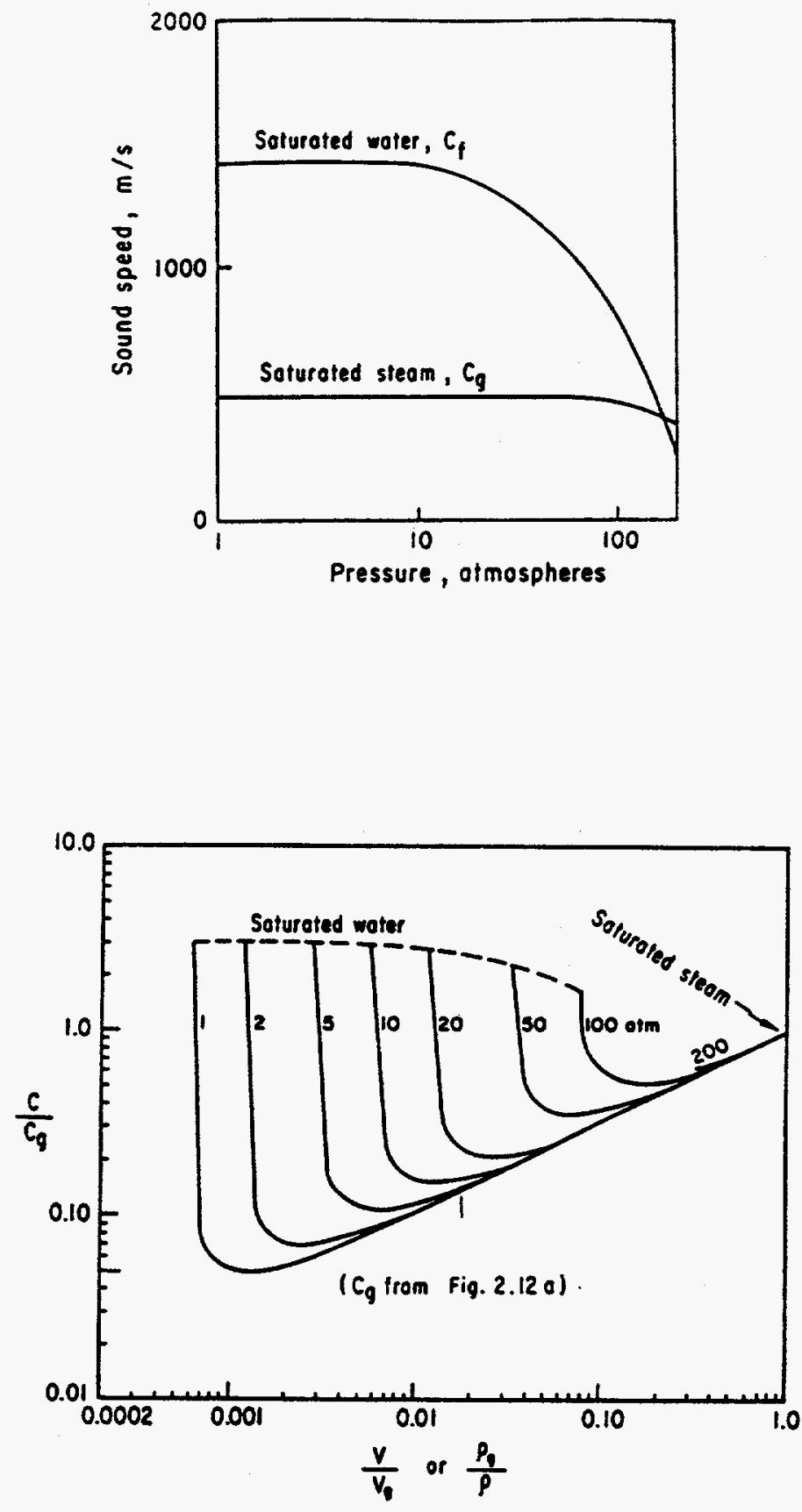

Figure A-1. The velocity of sound in: (a) saturated water and saturated steam, (b) twophase mixtures (homogeneous). Reference 2. 


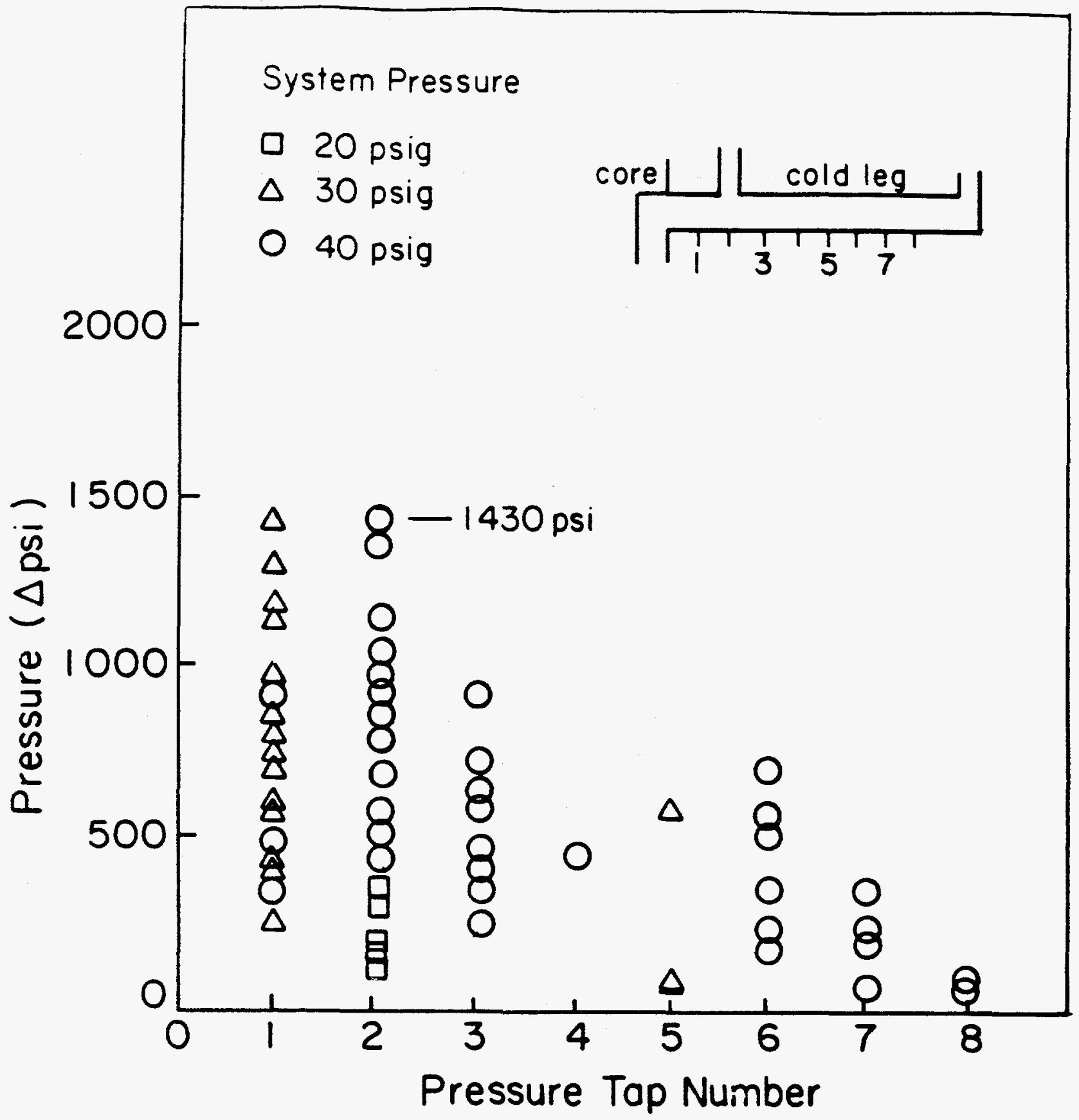

Figure A-2. The peak steam bubble collapse induced water hammer pressures observed in the simulated cold leg as a function of pressure tap location. The peak pressure for all water hammers measured in this experiment is 1430 psi. Equation A-2 yields a peak pressure of 1527 psi. Reference (13). 
There are some experiments to which the above recommendations can be compared. The first comparison was reported in Reference (13). A calculation much like that given above is shown along with the data in Figure A-2. This data was taken in a small, low pressure model of a PWR. A cartoon showing a schematic of the cold leg in this model where ECC was admitted and the pressure measured is also provided.

The most important things that we learned from these experiments is that scatter is always present, that it is very large, and the above calculation method is generally conservative. Calculating the pressure rise for this experiment using the rule of thumb yields,

$$
\Delta \mathrm{P}=2042 \mathrm{psi}
$$

so it too is slightly conservative for all the points measured.

If the study of the most limiting failure mode shows that the motion of a pipe limits, then the time the force acts is important too. The time it acts can be estimated as twice the transit time of the pressure wave from the impact front to the other end of the slug and back to the impact front. A rough calculation of this time using a sonic velocity of 4000 $\mathrm{ft} / \mathrm{sec}$ yields,

$$
\Delta \mathrm{t}=\frac{2 L_{s}}{C}
$$

$$
\approx \frac{2(2)}{4000} \approx \frac{1}{1000} \mathrm{sec}
$$

To measure such a brief transient requires good instrumentation. If a lower sonic velocity is used for the peak pressure calculation, a lower sonic velocity should be used to estimate the time that the pressure acts.

A second set of data is shown in Figure A-3. The scatter here is also considerable. Using equation (1-1), the $\mathrm{K}$ limit of one, and the rule of thumb of $50 \mathrm{psi} /(\mathrm{ft} / \mathrm{sec})$ of extinguished velocity, for the pressure rise (equation A-1), the peak pressure calculated for the apparatus is calculated to be,

$$
\Delta \mathrm{P}=1723 \text { psi. }
$$

This is for cold water. This is considerably higher than the highest data point shown on Figure (A-3). In retrospect, omitting the effects of any bubbles due to noncondensible gases originally in the steam, the reduction in flow velocity due to the contraction at the entrance to the tube, and the variability in the operator valve opening time probably accounts for both the scatter and general reduction in the measured peak pressure from that anticipated.

When extraordinary care is taken to define the system, reproducible and predictable experimental results can be obtained (17). The practical problem is no one ever has enough knowledge of the state of a real, full-sized engineering system to allow one to make a precise calculation of the severity of the water hammer. 


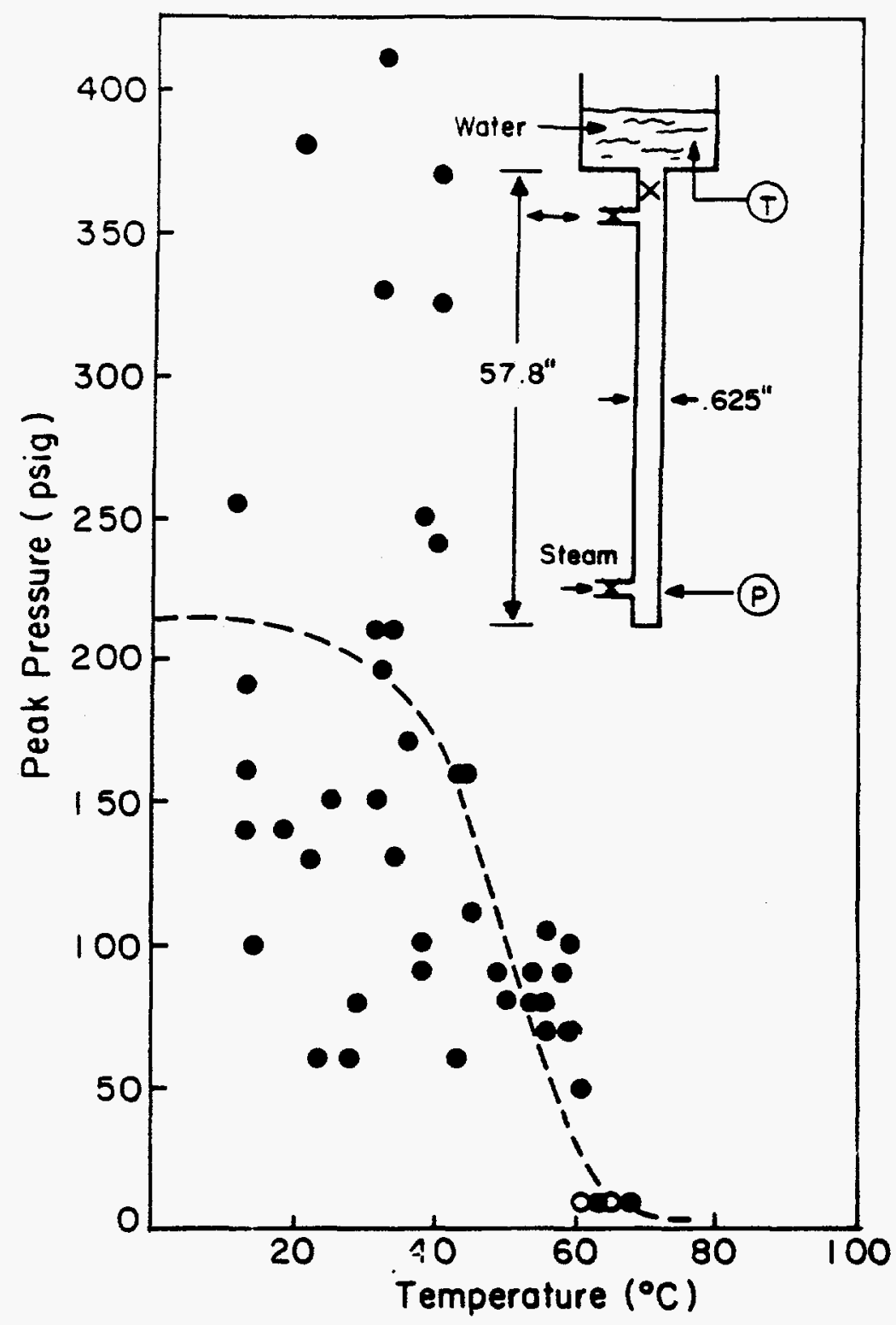

Figure A-3. Peak steam bubble collapse induced pressure measured in the apparatus shown at the upper right. Reference (16). 


\section{References}

1. Avallone, E.A., T. Baumeister III, "Marks' Standard Handbook for Mechanical Engineers" McGraw-Hill, 9th Edition. pp. 3-71. 1987.

2. Moody, F.J., "Introduction to Unsteady Thermofluid Mechanics" John Wiley and Sons, 1990. Chapter 9, page 405.

3. VanDuyne, D.A., W.Yow, J.W. Sabin, "Water Hammer Prevention, Mitigation and Accomodation. Volume I: Plant Water Hammer Experience" EPRI Report NP-6766; July, 1992. (This report is public, other reports are available to EPRI members).

4. Bjorge, R.W., Griffith, P., "Initiation of Water Hammer in Horizontal Pipes Containing Steam and Subcooled Water" Trans ASME, Interanational Journal of Heat Transfer. November, 1984. Vol. 106, pp. 835-840.

5. Swierzawski, T.J., Griffith,P., "Preventing Water Hammer in Large Horizontal Pipes Passing Steam and Water" Trans ASME Journal of Heat Transfer. Vol. III, November, 1989.

6. Lobo, C.O.A., Griffith, P., "Avoiding Steam Bubble Collapse Induced Water Hammer in the Auxilliary Piping of Steam Power Plants" Trans ASME Journal of Pressure Vessel Technology, Vol. 116, No. 1, February, 1994.

7. Chou, Y., Griffith, P., "Admitting Cold Water into Steam Filled Pipes Without Water Hammer Due to Steam Bubble Collapse". Nuclear Engineering and Design, Vol. 121, 1990, pp. 367-378.

8. Wolf, A.R., Sweeney, E., Griffith, P., "Passive Water Hammer in Pipes Due to Flashing". PVP, Vol. 231, ASME, June, 1992.

9. Erenturk, M., "The Simulation of Passive Water Hammer in Pipes". SM Thesis in Mechanical Engineering, M.I.T., June, 1996.

10. Liang, K.S., Griffith, P., "Experimental and Analytical Study of Direct Contact Condensation of Steam in Water". Nuclear Engineering and Design, Vol. 147, 1994, pp. 425-435.

11. Neumann, A., Griffith, P., "Forces on a Pipe Bend Resulting from Clearing a Pool of Liquid Upstream". PVP, Vol. 231, June, 1992.

12. Fenton, R.M., Griffith, P., "The Forces at a Pipe Bend Due to the Clearing of Water Trapped Upstream". ASME Piping and Pressure Vessel Conference, Vol. $\underline{19}$, June, 1990.

13. Jackobek, A.B., Griffith, P., "Investigation of Cold Leg Water Hammer in a PWR Due to the Admission of Emergency Core Cooling (ECC) During a Small Break LOCA".

NUREG/CR-3895, Sept., 1984.

14. Griffith, P., Silva, Robert J., "Steam Bubble Collapse Induced Water Hammer in Draining Pipes". PVP, Vol. 231, ASME, 1992. 
15. Izenson, M.G., Rothe, P.H., Wallis, G.B., "Diagnosis of Condensation-Induced Water Hammer". NUREG/CR-5220. Vol. 1, Vol. 2, 1988.

16. Perkins, G., "Peak Pressures Due to Bubble Collapse-Induced Water Hammer". SB Thesis in Mechanical Engineering, M.I.T., May, 1979.

17. Easom, B., "The Effect of Noncondensible Gas on Steam Bubble Collapse Induced Water Hammer". Ph.D. Thesis in Mechanical Engineering, M.I.T., June, 1992. 